\title{
Glial Dysfunction in the Mouse Habenula Causes Depressive- Like Behaviors and Sleep Disturbance
}

\author{
Wanpeng Cui, ${ }^{1}$ Hiroaki Mizukami, ${ }^{2}$ Michiko Yanagisawa, ${ }^{1}$ Tomomi Aida, ${ }^{1}$ Masatoshi Nomura, ${ }^{3}$ Yoshikazu Isomura, ${ }^{4}$ \\ Ryoichi Takayanagi, ${ }^{3}$ Keiya Ozawa, ${ }^{2}$ Kohichi Tanaka, ${ }^{1,5,6}$ and ${ }^{\odot H i d e n o r i ~ A i z a w a ~}{ }^{1}$ \\ ${ }^{1}$ Laboratory of Molecular Neuroscience, Medical Research Institute and ${ }^{6}$ Center for Brain Integration Research, Tokyo Medical and Dental University, 1-5- \\ 45 Yushima, Bunkyo-ku, Tokyo 113-8510 Japan, ${ }^{2}$ Division of Genetic Therapeutics, Center for Molecular Medicine, Jichi Medical University, 3311-1 \\ Yakushiji, Shimotsuke, 329-0498 Japan, ${ }^{3}$ Department of Medicine and Bioregulatory Science, Graduate School of Medical Science, Kyushu University, \\ Maidashi 3-1-1, Higashi-ku, Fukuoka 812-8582, Japan, ${ }^{4}$ Tamagawa University Brain Science Institute, 6-1-1 Tamagawa Gakuen, Machida, Tokyo, 194-8610 \\ Japan, and ${ }^{5}$ Core Research for Evolutional Science and Technology, Japan Science and Technology Agency, Sanbancho Building 5, Sanbancho, Chiyoda-ku, \\ Tokyo 102-0075, Japan
}

The lateral habenula $(\mathrm{LHb})$ regulates the activity of monoaminergic neurons in the brainstem. This area has recently attracted a surge of interest in psychiatry because studies have reported the pathological activation of the habenula in patients with major depression and in animal models. The LHb plays a significant role in the pathophysiology of depression; however, how habenular neurons are activated to cause various depression symptoms, such as reduced motivation and sleep disturbance, remain unclear. We hypothesized that dysfunctional astrocytes may cause LHb hyperactivity due to the defective uptake activity of extracellular glutamate, which induces depressivelike behaviors. We examined the activity of neurons in habenular pathways and performed behavioral and sleep analyses in mice with pharmacological and genetic inhibition of the activity of the glial glutamate transporter GLT-1 in the LHb. The habenula-specific inhibition of GLT-1 increased the neuronal firing rate and the level of c-Fos expression in the LHb. Mice with reduced GLT-1 activity in the habenula exhibited a depressive-like phenotype in the tail suspension and novelty-suppressed feeding tests. These animals also displayed increased susceptibility to chronic stress, displaying more frequent avoidant behavior without affecting locomotor activity in the openfield test. Intriguingly, the mice showed disinhibition of rapid eye movement sleep, which is a characteristic sleep pattern in patients with depression. These results provide evidence that disrupting glutamate clearance in habenular astrocytes increases neuronal excitability and depressive-like phenotypes in behaviors and sleep.

Key words: astrocytes; depression; glutamate transporters; habenula; monoamines; rapid eye movement sleep

\section{Introduction}

Major depression is a pervasive disorder that displays a combination of symptoms, including reduced motivation, appetite loss,

\footnotetext{
Received April 11, 2014; revised 0ct. 9, 2014; accepted 0ct. 23, 2014.

Author contributions: K.T. and H.A. designed research; W.C., H.M., M.Y., T.A., and H.A. performed research;M.N., Y.I., R.T., and K.O. contributed unpublished reagents/analytic tools; W.C. and H.A. analyzed data; K.T. and H.A. wrote the paper.

This work was supported by the Mitsui Life Social Welfare Foundation, the Takeda Science Foundation, the Naito Foundation, the Uehara Memorial Foundation, the Suzuken Memorial Foundation, the KANAE foundation for the promotion of medical sciences, the Inamori Foundation, and the Brain Science Foundation; by a Grant-in-Aid for Young Scientists (B) (KAKENHI24700350), a Grant-in-Aid for Scientific Research on Innovative Areas (KAKENHI26112010), and a Grant-in-Aid for Scientific Research (C) (KAKENHI26430008) from the Ministry of Education, Culture, Sports, Science and Technology to H.A.; and by the Core Research for Evolutional Science and Technology of Japan Science and Technology Agency to K.T. A portion of this study is the result of "Understanding of molecular and environmental bases for brain health" performed under the Strategic Research Program for Brain Sciences by Ministry of Education, Culture, Sports, Science and Technology. We thank Masahiko Watanabe for the anti-GLT-1 and anti-GLAST antibodies; Jinghui Dong and Douglas A. Coulter for pZac-Gfa104-EGFP plasmid DNA; Hitoshi Okamoto for discussion; and Harumi Ishikubo and Masako Hidaka for technical support.

The authors declare no competing financial interests.

Correspondence should be addressed to either Dr. Hidenori Aizawa or Dr. Kohichi Tanaka, Tokyo Medical and Dental University, 1-5-45 Yushima, Bunkyo-ku, Tokyo 113-8510 Japan, E-mail: haizawa.aud@mri.tmd.ac.jp or tanaka.aud@mri.tmd.ac.jp.

DOI:10.1523/JNEUROSCI.1465-14.2014

Copyright $\odot 2014$ the authors $\quad 0270-6474 / 14 / 3416273-13 \$ 15.00 / 0$
}

and sleep disturbance (Kessler et al., 2003). This heterogeneity of depressive symptoms complicates the identification of the underlying neural pathways.

The lateral habenula ( $\mathrm{LHb}$ ) has been implicated in the regulation of monoaminergic systems (Hikosaka, 2010), which play major roles in the efficacy of antidepressant reagents in depression (Berton and Nestler, 2006). This nucleus has recently attracted a surge of interest as a neural substrate for the underlying pathophysiology of depression because studies have reported increased activity in the habenula in major depression (Morris et al., 1999; Roiser et al., 2009) and in a helpless rat model for depression ( $\mathrm{Li}$ et al., 2011). These findings, together with the antidepressant effects of LHb lesions in rats (Yang et al., 2008) or deep brain stimulation (DBS) of the habenular circuit in rats ( $\mathrm{Li}$ et al., 2011) and humans (Sartorius et al., 2010), support the hypothesis that hyperactivation of the habenula plays a role in the pathophysiology of depression.

The molecular and cellular mechanisms that upregulate habenular activity remain unclear, despite accumulating evidence for a pivotal role of hyperactivated habenula in depression. Previous studies have reported that LHb neurons are heterogeneous in their pattern of activity, such as spontaneously generated tonic 
firing, burst oscillations of action potentials, and silence in vitro (Wilcox et al., 1988; Kim and Chang, 2005). These firing patterns, which are outputs from the LHb, are under the influence of the excitatory and inhibitory inputs from structures, such as the entopeduncular nucleus (the rodent homolog of the internal segment of the globus pallidus), the lateral hypothalamus, and the diagonal band of Broca (Meye et al., 2013).

Interactions between neurons and glia affect neuronal excitability via the modulation of synaptic transmissions in local circuits (Fields and Stevens-Graham, 2002). Glutamate at the synapse mediates excitatory transmission in the habenula (Li et al., 2011) and is cleared primarily by astrocytes expressing glutamate transporters, such as GLT-1 (EAAT2 in humans) (Tanaka et al., 1997; Popoli et al., 2011). We hypothesized that defects in glutamate uptake activity by astrocytes would increase the excitability of habenular neurons due to excessive glutamate at the synapse.

We demonstrate that mice lacking GLT-1 specifically in habenular astrocytes exhibit hyperactivation of the habenula leading to multiple symptoms characteristic of a depressive-like phenotype, such as behavioral despair, avoidant behaviors under stress, and the disinhibition of rapid eye movement (REM) sleep.

\section{Materials and Methods}

Subjects

All of the experiments were performed in accordance with the Animal Experiment and Recombinant DNA Experiment Plans approved by the Committees of Tokyo Medical and Dental University. The animals were maintained throughout the experiments on a $12 \mathrm{~h}$ light/dark cycle (lights on at 8:00 and off at 20:00).

Male C57BL/6J (8- to 12-week-old, 24-28 g, CLEA Japan) and floxed GLT-1 mice (see below) were used. Mice carrying a floxed GLT-1 allele $\left(G L T-1^{\text {flox/+ }}\right)$ were generated via the insertion of one loxP site into intron 3 and another loxP site into intron 4 of embryonic stem cells from the 129Sv strain. GLT-1 ${ }^{\text {flox/flox }}$ mice were obtained by crossing heterozygotes that had previously been outbred with a wild-type C57BL/6J strain (CLEA Japan) for more than six generations before this study. We used 12- to 16-week-old male mice for all of the behavioral tests.

\section{Genotyping the animals}

Animal genotypes were determined via amplification of the DNA fragments peculiar to the modified allele using genomic DNA as a template with the following primer sets: forward primer, 5'-CCCATCCTTAC ACCAGAAAC- $3^{\prime}$ and reverse primer, $5^{\prime}$-TCTTTCTACCAGGCTGGC TT-3'.

\section{Quantitative RT-PCR}

Mice were killed using pentobarbital (100 mg/kg, i.p.) and perfused with cold PBS. Using a surgical blade, the habenula was dissected from 1-mmthick coronal sections of the brain, which were prepared using a brain matrix (RBM-2000c, ASI Instruments). Total RNA (1 $\mu \mathrm{g})$ was isolated using TRIzol reagent (Invitrogen) and used for RT (PrimeScript RT with gDNA Eraser, Takara Bio). The quantitative PCRs were performed and analyzed using a LightCycler 480 System II (Roche Applied Bioscience) with SYBR Premix ExTaq II (Takara Bio). The following primers were used: solute carrier family 1, member 2 (Slc1a2, synonym for GLT-1, GenBank accession number NM_001077514.3), forward 5'-GGTCATCTTGGATGGAGGTC- $3^{\prime}$ and reverse $5^{\prime}$-ATACTGGCTGCACCAATGC-3'; solute carrier family 1, member 3 (Slc1a3, synonym for GLAST, GenBank accession number NM_148938.3), forward 5' GTCGCGGTGATAATGTGGTA- ${ }^{\prime}$ ' and reverse $5^{\prime}$-AATCTTCCCTGCGATCAAGA-3'. Every sample was run in duplicate.

We used a DNA plasmid containing one copy of murine partial cDNAs for GLT-1 and GLAST as the template for mRNA quantification. Partial cDNAs for each gene were PCR-amplified using the above primer sets and tandemly subcloned into the XhoI-EcoRI sites of pcDNA3.1 (+) (Invitrogen). Serial dilutions of the plasmid DNA ranging from $1.2 \times$
$10^{-8}$ to $1.92 \times 10^{-11}$ pmol were used as templates to make standard curves for these two genes. The amount of each target gene in $50 \mathrm{ng}$ of total RNA was calculated based on the threshold cycle $\left(\mathrm{C}_{t}\right)$ value referencing the standard curve.

\section{Generating the $A A V$ vectors}

Constructing the plasmid DNA. A NotI-EcoRI fragment of EGFP and an EcoRI-HindIII fragment of Cre cDNAs were PCR-amplified and subcloned into the corresponding sites of the pBluescript II vector (Agilent Technologies) to generate pBSII-EGFP-Cre. A NotI-HindIII fragment of EGFP cDNA in pZac-Gfa104-EGFP (Ortinski et al., 2010) was replaced with an EGFP-Cre cDNA fragment excised from pBSII-EGFP-Cre to generate pZac-Gfa104-EGFP-Cre.

Viral vector production. Adeno-associated virus vectors (AAVs) were produced by triple-plasmid transfection of 293 cells (Agilent Technologies) using either pZac-Gfa104-EGFP or pZac-Gfa104-EGFP-Cre, the helper plasmid for adenovirus genes (Agilent Technologies) and the helper plasmid for AAV8 (Yagi et al., 2011). The vector stocks were purified using cesium chloride density gradient ultracentrifugation, and the titer was determined using dot blotting and real-time PCR as described previously (Ishiwata et al., 2009). The AAV vector stocks contained $\sim 4-9 \times 10^{12}$ genome copies $/ \mathrm{ml}$.

\section{Histology}

Animals were deeply anesthetized with pentobarbital $(100 \mathrm{mg} / \mathrm{kg}$, i.p.) and fixed using transcardiac perfusion of $4 \%$ PFA in $0.1 \mathrm{M}$ PBS, pH 7.4. After postfixation overnight in the same fixative, $50-\mu \mathrm{m}$-thick sections (100 $\mu \mathrm{m}$ apart) were cut using a vibratome and processed for immunohistochemistry. Polyclonal rabbit anti-GLAST (1:1000 dilution, a gift from Professor Watanabe, Hokkaido University) (Shibata et al., 1997), polyclonal rabbit anti-GLT-1 (Yamada et al., 1998), polyclonal goat antiGLT-1 (1:1000, a gift from Professor Watanabe, Hokkaido University), monoclonal mouse anti-NeuN (1:1000, MAB377, Millipore), monoclonal mouse anti-neurofilament 200 (1:400, N0142, Sigma-Aldrich), mouse monoclonal anti-S100 $\beta$ (1:500, S2532, Sigma-Aldrich), rabbit polyclonal anti-GFAP (1:1000, Z0334, Dako), polyclonal rabbit anti-cFos (1:1000, sc-52, Santa Cruz Biotechnology), polyclonal goat anti-serotonin (1:1000, 20079, ImmunoStar), monoclonal mouse antityrosine hydroxylase (1:2000, 22941, ImmunoStar), goat anti-rabbit IgG-AlexaFluor-488 (1:500, A-11034, Invitrogen), donkey anti-goat IgG-AlexaFluor-488 (1:500, A-11055, Invitrogen), goat anti-mouse IgGAlexaFluor-594 (1:500, A-11005, Invitrogen), goat anti-rabbit IgGAlexaFluor-594 (1:500, A-11012, Invitrogen), donkey $\mathrm{F}\left(\mathrm{ab}^{\prime}\right) 2$ fragment anti-rabbit IgG-peroxidase (1:800, ab98493, Abcam), donkey anti-goat IgG-peroxidase (1:1000, 705-035-147, Jackson ImmunoResearch Laboratories), and donkey anti-mouse IgG-peroxidase (1:1000, 715-035-150, Jackson ImmunoResearch Laboratories) antibodies were used. For single staining, the c-Fos signal was visualized using a DAB-nickel substrate, and sections were counterstained with neutral red. For double-labeling, first, we visualized immunoreactivity against serotonin or tyrosine hydroxylase with $\mathrm{DAB}$ and then processed the tissues with the same procedure used in the single-staining of c-Fos. Some sections with fluorescent labeling were counterstained with DAPI.

The number of c-Fos-positive cells was counted by a person blinded to the group assignment. We confirmed that the entire extent of the brain structures, which include the $\mathrm{LHb}$, the rostromedial tegmental nucleus (RMTg), the ventral tegmental area (VTA), the substantial nigra pars compacta $(\mathrm{SNc})$, the median raphe (MR) and the dorsal raphe (DR), were covered by 4 (for RMTg) or 5 (for LHb, VTA/SNc, MR, and DR) consecutive $50-\mu \mathrm{m}$-thick sections with $100 \mu \mathrm{m}$ intervals, which were prepared from fixed brain samples. Sections from different groups were carefully matched between subjects using anatomical landmarks, such as the ventricular and pial surfaces. The total number of c-Fos-positive cells was counted in 4 (from 4.1 to $4.6 \mathrm{~mm}$ posterior to the bregma for RMTg) or 5 serial sections at $100 \mu \mathrm{m}$ intervals (from 1.2 to $2.1 \mathrm{~mm}$ posterior to the bregma for LHb; 4.1 to $4.9 \mathrm{~mm}$ posterior to the bregma for MR and $\mathrm{DR}$; from 2.9 to $3.8 \mathrm{~mm}$ posterior to the bregma for VTA/SNc) according to the brain atlas (Paxinos and Franklin, 2008) 
Experiment 1: effect of a glutamate transporter inhibitor on the activity of $\mathrm{LHb}$ neurons

To determine the effect of the glutamate transporter inhibitor dihydrokainic acid (DHK) (D1064, Sigma-Aldrich) or of PBS on the activity of $\mathrm{LHb}$ neurons, male $\mathrm{C} 57 \mathrm{BL} / 6 \mathrm{~J}$ mice were anesthetized with urethane (1.4 $\mathrm{g} / \mathrm{kg}$ ) for single-unit recordings, and their body temperature was maintained with a heating pad. A glass electrode (BF150-75-10, Sutter Instrument) with a blunt tip (5-10 M $\Omega$ ) was filled with PBS or with $10 \mathrm{~mm}$ DHK in PBS and inserted into the $\mathrm{LHb}(1.65 \mathrm{~mm}$ posterior and $0.45 \mathrm{~mm}$ lateral to the bregma, $2.45-2.70 \mathrm{~mm}$ deep) using a vertical micromanipulator (MO-10, Narishige). The signal was amplified using an amplifier (EX4400, Dagan) and sampled at $20 \mathrm{kHz}$ (final gain, 2000; bandpass filter, $300-10 \mathrm{kHz}$ ). At the end of each experiment, a glass pipette filled with $2 \%$ pontamine sky blue (C8679-25G, Sigma-Aldrich) was inserted to the $\mathrm{LHb}$ with the same coordinate and marked the recording site by application of $-10 \mu \mathrm{A}$ direct current for $15 \mathrm{~min}$. The center of the resulting dye mark was used as a reference point to identify the locations of other recording sites in the animal on $50 \mu \mathrm{m}$ vibratome sections stained with neutral red (see above).

Experiment 2: effect of bilateral intra-LHb injection of glutamate transporter inhibitor on $c$-Fos expression in the brainstem nuclei To study the effect of DHK (Sigma-Aldrich) on c-Fos expression, wildtype C57BL/6J mice were anesthetized with urethane (1.4 g/kg, i.p.) and immobilized in a stereotaxic apparatus (SR-8N, Narishige). Two tiny holes were made in the skull and dura mater $(1.65 \mathrm{~mm}$ posterior and 0.9 $\mathrm{mm}$ lateral to the bregma). A fine glass pipette filled with a solution containing PBS or $10 \mathrm{~mm}$ DHK in PBS ( $\mathrm{pH}$ adjusted to 7.0) was placed $2.65 \mathrm{~mm}$ deep to target the $\mathrm{LHb}$ using a $10^{\circ}$ tilted micromanipulator (model 1760-61, David Kopf Instruments). Solutions were iontophoretically applied using a $-2 \mu \mathrm{A}$ direct current for $7 \mathrm{~min}$. We killed the animals $2 \mathrm{~h}$ after the injection to perform c-Fos immunohistochemistry (see above).

\section{Experiment 3: effect of bilateral intra- $\mathrm{LHb}$ injection of a} glutamate transporter inhibitor on behavior in the tail suspension test

To enable DHK injection to the bilateral LHb in awake mice without anesthesia, we inserted a glass pipette filled with DHK or PBS solution to the $\mathrm{LHb}$ of awake mice whose heads were transiently fixed to the stereotaxic apparatus (SR-8N, Narishige).

For the head-restrained preparation, a $30 \times 15 \times 1 \mathrm{~mm}$ aluminum alloy plate with a single hole ( $8 \mathrm{~mm}$ in diameter) at the center was surgically attached to the skull as described previously under pentobarbital anesthesia (50 mg/kg, i.p.) (Isomura et al., 2009). The animals were kept in their home cages for $>7 \mathrm{~d}$ after recovery from surgery. The day before the DHK solution injection, the animals were subjected to a second surgery in which two tiny holes were made in the skull and dura mater (1.65 $\mathrm{mm}$ posterior and $0.9 \mathrm{~mm}$ lateral to the bregma) under $2 \%$ isoflurane anesthesia $(\mathrm{v} / \mathrm{v})$. The hole was covered with silicon sealant until the injection began. The injection was administered as described above to the animals, which were accommodated in a custom-made container with a head restraint. The animals were subjected to the tail suspension test 30 min after injection.

For the tail suspension test, the mice were suspended by the tail and attached to a bar $30 \mathrm{~cm}$ above the floor. Movement was monitored for 6 min using a charge-coupled device camera, and the duration of their immobility was scored and analyzed using ImageJ TS software (O’Hara \& Co.).

\section{Experiment 4: effect of GLT-1 gene deletion in the bilateral $\mathrm{LHb}$} on the activity of LHb neurons

To delete the GLT- 1 specifically in the LHb astrocytes, we injected $0.15 \mu \mathrm{l}$ of AAV solution diluted in PBS $\left(2.25-2.40 \times 10^{12}\right.$ genome copies $\left./ \mathrm{ml}\right)$ to each side of the LHb $(1.65 \mathrm{~mm}$ posterior and $0.9 \mathrm{~mm}$ lateral to the bregma, $2.65 \mathrm{~mm}$ deep using a $10^{\circ}$ tilted micromanipulator) in 8-weekold male GLT-1 ${ }^{\text {flox/flox }}$ mice using a fine glass electrode connected to an infusion pump (KDS101, KD Scientific) using the same procedure described in Experiment 2 under pentobarbital anesthesia $(50 \mathrm{mg} / \mathrm{kg}$, i.p.).
After incubation for 4 weeks, the mice were subjected to single-unit recordings.

For the single-unit recording in the mice after AAV injection, all the recordings were conducted using the same procedure described in Experiment 1 , except that the glass electrodes with higher resistance (10-15 $\mathrm{M} \Omega$ ) were filled with $2 \%$ pontamine sky blue in $0.5 \mathrm{~m}$ sodium acetate. The recording sites were labeled by iontophoretical application of pontamine sky blue using a $-10 \mu \mathrm{A}$ direct current for $15 \mathrm{~min}$.

\section{Experiment 5: effect of GLT-1 gene deletion in the bilateral $\mathrm{LHb}$ on the despair-and conflict-based behavioral tests}

We generated the mice with AAV injection using the same procedure described in Experiment 4. After incubation for 4 weeks, the mice were subjected to a series of behavioral tests, which were all performed after habituation of the mice to the test room for at least $1 \mathrm{~h}$, in the following order:

Open-field test. The animals were placed in the corner of an open field $(50 \times 50 \times 40 \mathrm{~cm})$ at 70 lux illumination. Animal movement was detected for $30 \mathrm{~min}$ using a charge-coupled device camera to record an image every $0.5 \mathrm{~s}$. The images were processed with custom software (O'Hara \& Co.).

Tail suspension test. This test was performed using the procedure described in Experiment 3. To determine the effect of fluoxetine (F132, Sigma-Aldrich), which is a serotonin-selective reuptake inhibitor, the mice were injected with either vehicle (saline) or fluoxetine (concentration, $2 \mathrm{mg} / \mathrm{ml}$ in saline; injection volume $0.24-0.30 \mathrm{ml}$ ) intraperitoneally at a dose of $20 \mathrm{mg}$ per $\mathrm{kg}$ of body weight, $30 \mathrm{~min}$ before the test. We killed some of the animals for c-Fos analysis $2 \mathrm{~h}$ after the test.

Novelty-suppressed feeding test. This test was performed as described previously (Santarelli et al., 2003), with slight modifications. Briefly, the animals were deprived of all food in the home cage $24 \mathrm{~h}$ before testing. One food pellet was placed on a piece of round filter paper $(12.5 \mathrm{~cm}$ in diameter) at the center of the acrylic testing chamber $(50 \times 50 \times 40$ $\mathrm{cm}$ ), with the floor covered with bedding. Then, the animal was placed in a corner of the chamber. The latency to approach and to begin feeding on the food was measured for a maximum of $5 \mathrm{~min}$ under 140 lux illumination.

Social avoidance test after chronic social defeat stress. A daily defeat stress was applied for $10 \mathrm{~d}$ as described previously (Berton et al., 2006). Briefly, an intruder male mouse was subjected to physical contact for $10 \mathrm{~min}$, followed by nonphysical and sensory contact for $24 \mathrm{~h}$ using a perforated Plexiglas partition with an unfamiliar aggressor ICR mouse in each defeat episode. For the non-defeated control, the mice were housed in pairs and were separated by the partition. The social avoidance test was performed in an arena $(50 \times 50 \times 40 \mathrm{~cm})$ with a mesh cage in the presence or absence of an unfamiliar aggressor ICR mouse on day 11 as reported previously (Berton et al., 2006). The interaction ratio was calculated as $100 \times$ (interaction time, unfamiliar aggressor)/(interaction time, empty cage) (Krishnan et al., 2007). After this behavioral test, we killed the animals to perform GLT-1 and c-Fos immunohistochemistry (see above).

\section{Experiment 6: effect of GLT-1 gene deletion in the bilateral $\mathrm{LHb}$ on sleep}

We generated the mice with AAV injection using the procedure described in Experiment 4. After incubation for 4 weeks, electroencephalograms (EEGs) and electromyograms (EMGs) were recorded in freely behaving mice to analyze the sleep pattern in the mice with AAV injection. We implanted a Teflon-coated silver wire above the primary somatosensory cortex $(1.5 \mathrm{~mm}$ posterior and $1.5 \mathrm{~mm}$ lateral to the bregma), two electrodes in the trapezius muscle and one electrode above the cerebellum, which is a reference electrode for EEG recording for sleep staging, under $2 \%$ isoflurane anesthesia $(\mathrm{v} / \mathrm{v})$. The animals were transferred to the recording chamber in a sound-attenuating box after a recovery period of at least $5 \mathrm{~d}$. Signals were amplified using a preamplifier (TLC2774c, Texas Instruments) and a primary amplifier (EX4-400, Dagan) and sampled at $1000 \mathrm{~Hz}$ (final gain, 2000; bandpass filter, $0.1-500 \mathrm{~Hz}$ ). 


\section{Data analysis}

Evaluation of intra-LHb injection. We initially conducted a pilot experiment to optimize the coordinate for intra-LHb injection of the solution using a glass pipette filled with dyes, such as $2 \%$ pontamine sky blue and $2 \%$ biotinylated dextran amine (BDA-10000, Invitrogen) (data not shown) and found that the coordinate used in Experiments 2-6 (1.65 $\mathrm{mm}$ posterior and $0.9 \mathrm{~mm}$ lateral to the bregma, $2.65 \mathrm{~mm}$ deep using a $10^{\circ}$ tilted micromanipulator) provided the maximal success rate to target the $\mathrm{LHb}$ (19 of $22,86.4 \%$ ). To identify the case with successful targeting of the LHb, we examined the distribution of c-Fos- and EGFP-positive cells to determine the areas affected by intra-LHb injections of DHK and AAV, respectively. The criterion for successful injection was that the center of distribution in c-Fos- and EGFPpositive cells was within the LHb on both sides. We only analyzed the cases with successful injection in all experiments.

We analyzed all the samples with intra$\mathrm{LHb}$ injection of PBS due to the absence of markers indicating the area affected by the PBS solution.

Analysis of sleep stages. The behavioral states of the animals were classified as awake, REM sleep, or non-REM sleep according to previously described procedures (Aizawa et al., 2013b). To determine whether the circadian data displayed unimodal distribution, we analyzed the sleep stage data with 4 s epochs using Rayleigh's test of randomness against a unimodal distribution (Fisher, 1993). We used circStat MATLAB (MathWorks) scripts to calculate Rayleigh's $Z$ value (Berens, 2009). The approximation $p=e^{-Z}$ was adopted because the number of samples invariably exceeded 50 (Fisher, 1993).

Spike sorting. Single-unit recording data were processed to isolate spike events using an automatic spike-sorting program, which combined principal component analysis with a robust variational Bayesian analysis for spike clustering (Takekawa et al., 2012). The sorted spike clusters were combined, divided, and discarded manually to refine single-neuron clusters using Klusters and NeuroScope (Hazan et al., 2006). Analyses of unit-recording data, except for spike sorting, were conducted using custom-made scripts for MATLAB.

Statistical analysis. All the statistical analyses were performed using SPSS Statistics 19 software (IBM). The binary comparisons were tested using the two-tailed Mann-Whitney $U$ test, and comparisons between more than two groups were tested using one-way ANOVA, followed by Tukey's post hoc test for multiple comparisons. Statistical significance was defined as a value of $p<0.05$.

\section{Results}

Glial glutamate transporter inhibition increased lateral habenular neuron firing in mice

We examined the expression of known astrocyte markers in the $\mathrm{LHb}$ to gain molecular insight into astrocyte function. The $\mathrm{LHb}$ expressed a much lower level of GFAP than the medial habenula $(\mathrm{MHb})$; however, $\mathrm{S} 100 \beta$ was expressed uniformly in the $\mathrm{MHb}$ and in the LHb (Fig. 1A). The LHb expressed glutamate transporters, such as GLT-1 (Fig. 1B) and GLAST (Fig. 1C), to a greater extent compared with the MHb (asterisks in Fig. $1 B, C$ ). Quantitative RT-PCR analysis revealed that GLT-1 mRNA was expressed more abundantly than GLAST in the habenula (Fig. $1 D$; Mann-Whitney $U$ test, $U_{4,4}=0.0, p=0.0286$ ), suggesting a
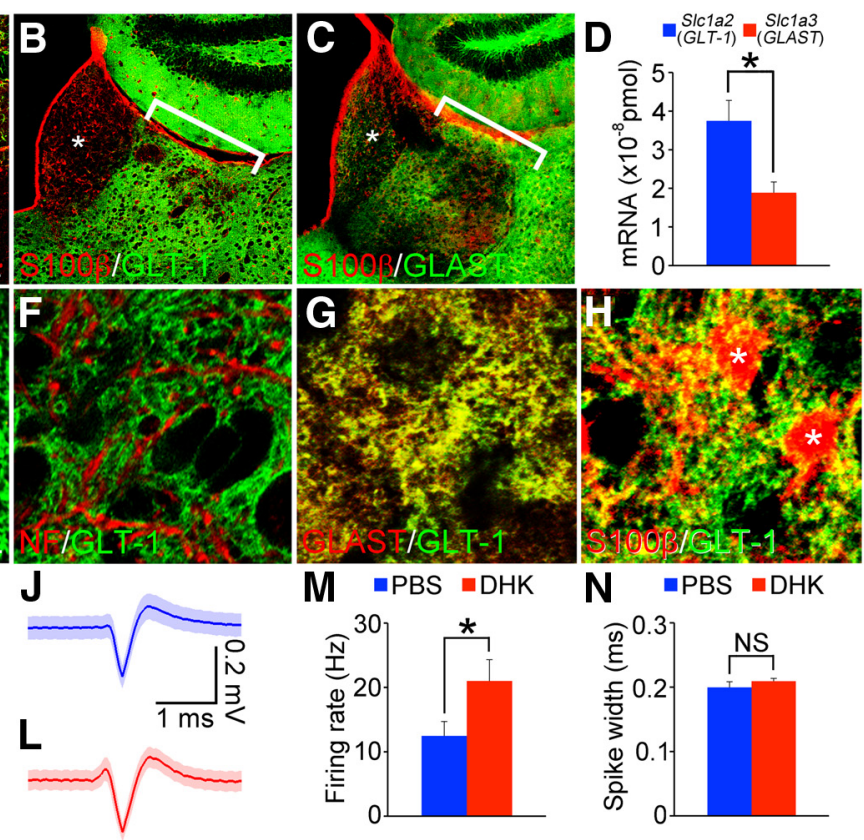

M $=\mathrm{PBS}=\mathrm{DHK}$
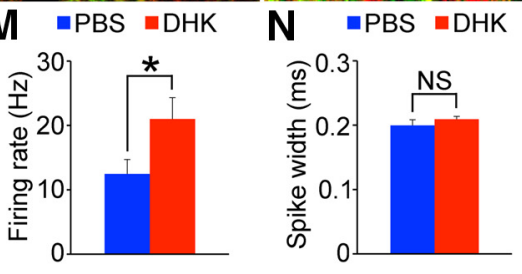

Figure 1. Inhibition of the glutamate transporter GLT-1 activates lateral habenular neurons. $\boldsymbol{A}-\boldsymbol{C}$, Coronal sections of the mouse (hynonym for GLAST, red) expressed in the habenula $(N=4) . \boldsymbol{E}-\boldsymbol{H}$, High magnification of coronal sections of the

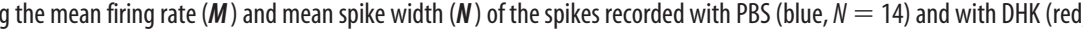
$N=10)$. ${ }^{*}$ Significant difference ( $p<0.05$, two-tailed Mann-Whitney U test). Error bars indicate SEM. NS, Not significant. Scale bars: $\boldsymbol{A}$ (applies to $\boldsymbol{B}, \boldsymbol{C}), 200 \mu \mathrm{m} ; \boldsymbol{E}$ (applies to $\boldsymbol{F}-\boldsymbol{H}$ ), $10 \mu \mathrm{m}$.

dominant role of GLT-1 in regulating LHb excitability via its ability to clear glutamate from the synaptic cleft. Previous studies have provided evidence that GLT-1 is specifically expressed in the astrocytes but not in neurons in many brain regions, except for hippocampus (Danbolt et al., 1992; Levy et al., 1993; Rothstein et al., 1994; Chaudhry et al., 1995; Lehre et al., 1995; Chen et al., 2004). To examine whether GLT- 1 is specifically expressed in the astrocytes but not in neurons in the LHb, we performed doublelabeling of GLT-1 and the neuronal marker proteins, such as NeuN (Mullen et al., 1992) and neurofilament (Debus et al., 1983) or the astrocyte markers, such as GLAST (Chaudhry et al., 1995; Shibata et al., 1997) and S100 $\beta$ (Ludwin et al., 1976; Haan et al., 1982). The results demonstrated that GLT-1 protein distribution (Fig. 1E,F, green) rarely overlapped with that of NeuN (Fig. $1 E$, red) and neurofilament (Fig. $1 F$, red), whereas immunoreactivity in neuropils of the LHb displayed colocalization of GLT-1 (Fig. $1 G, H$, green) with GLAST (Fig. $1 G$, red) and S100 $\beta$ (Fig. $1 H$, red). These results suggested that GLT- 1 was specifically expressed in the astrocytes but not in neurons of the LHb.

Next, we investigated the effects of GLT-1 inhibition on LHb neuronal activity by measuring the responses of the LHb neurons to the GLT-1 inhibitor DHK (Arriza et al., 1994). Single-unit activity in the $\mathrm{LHb}$ neurons was recorded using a glass pipette filled with PBS or DHK solution, which passively diffuses toward the region surrounding the electrode tip (Ji and Shepard, 2007). $\mathrm{LHb}$ neurons responded to DHK with higher firing rates (Fig. $1 \mathrm{~K}, M$; Mann-Whitney $U$ test, $\left.U_{14,10}=33.0, p=0.0326\right)$ compared with those rates in response to PBS (Fig. $1 I, M$ ). We did not 


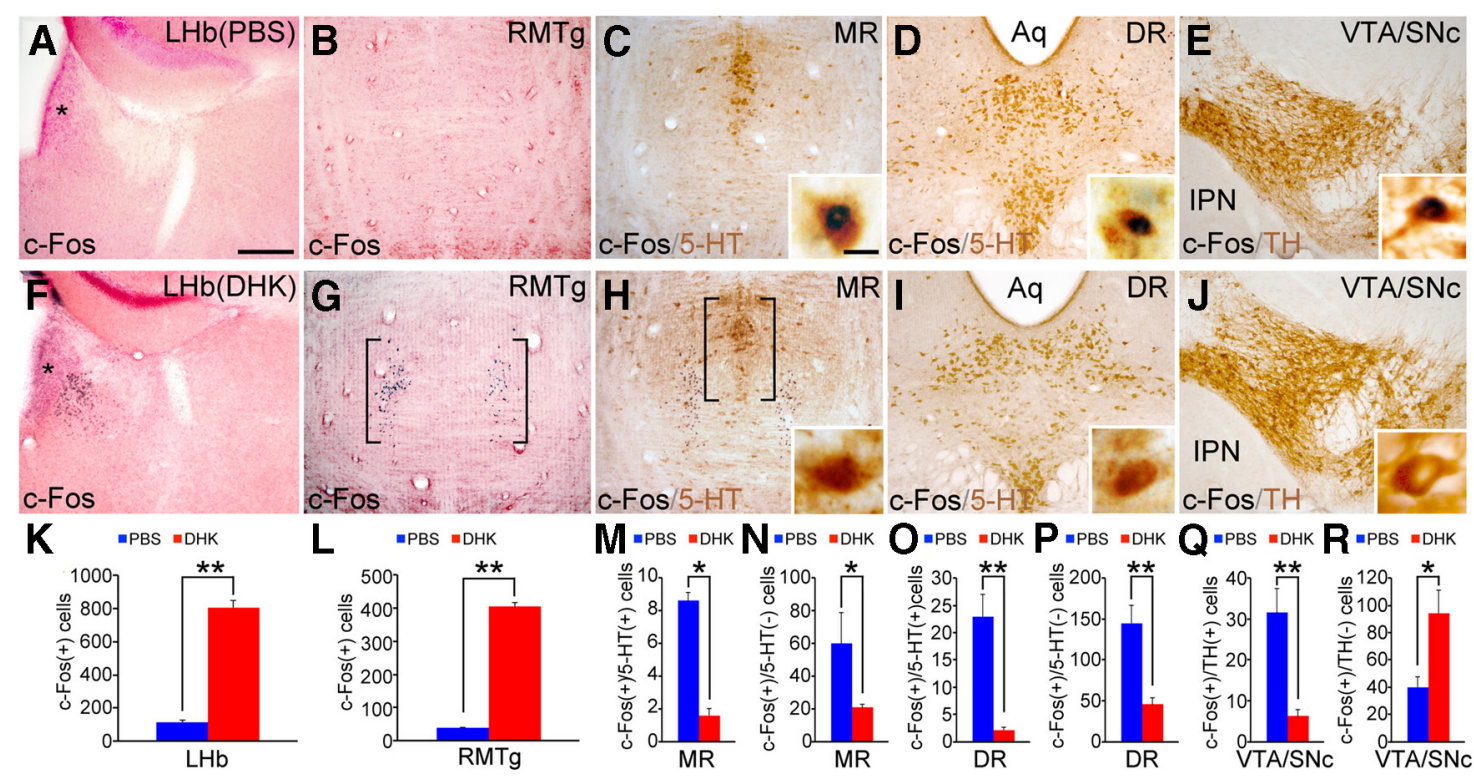

Figure 2. Effect of the activated LHb on c-Fos expression in the brainstem nuclei. $\boldsymbol{A}-\boldsymbol{J}$, Coronal sections of the $L H b(\boldsymbol{A}, \boldsymbol{F})$, the $\operatorname{RMTg}(\boldsymbol{B}, \boldsymbol{G})$, the MR $(\boldsymbol{C}, \boldsymbol{H})$, the DR $(\boldsymbol{D}, \boldsymbol{I})$, and the VTA/SNc $(\boldsymbol{E}, \boldsymbol{J})$ of the animals that received injections of PBS $(\boldsymbol{A}-\boldsymbol{E})$ or DHK $(\boldsymbol{F}-\boldsymbol{J})$ to the $L H b$ showing the expression of $\mathrm{C}-\mathrm{Fos}(\boldsymbol{A}-\boldsymbol{J}$, black), serotonin $(5-H \mathrm{H}, \boldsymbol{C}, \boldsymbol{D}, \boldsymbol{H}, \boldsymbol{I}$, brown), and tyrosine hydroxylase (TH, $\boldsymbol{E}, \boldsymbol{J}$, brown), $\boldsymbol{C}-\boldsymbol{E}, \boldsymbol{H}-\boldsymbol{J}$, Insets, Representative cells labeled by $5-H \mathrm{HT}(\boldsymbol{C}, \boldsymbol{D}, \boldsymbol{H}, \boldsymbol{I})$ or by $\mathrm{TH}(\boldsymbol{E}, \boldsymbol{J}) . \boldsymbol{A}, \boldsymbol{F}$, Asterisks indicate the medial habenula. $\boldsymbol{G}, \boldsymbol{H}$, Brackets indicate the RMTg and the MR, respectively. $\boldsymbol{A}, \boldsymbol{B}, \boldsymbol{F}, \boldsymbol{G}$, Sections were counterstained with neutral red. Aq, Cerebral aqueduct; IPN, interpeduncular nucleus. $\boldsymbol{K}-\boldsymbol{R}$, Bar graphs represent the mean number of c-Fos $(+)$ cells in the $\mathbf{L H b}(\boldsymbol{K})$ and in the RMTg $(\boldsymbol{L}) ; \mathrm{C}-\mathrm{Fos}(+) / 5-\mathrm{HT}(+)$ cells $(\boldsymbol{M})$ and c-Fos $(+) / 5-\mathrm{HT}(-)(\boldsymbol{N})$ in the MR; $\mathrm{c}-\mathrm{Fos}(+) / 5-\mathrm{HT}(+)$ cells $(\boldsymbol{O})$ and $\mathrm{C}-\mathrm{Fos}(+) / 5-\mathrm{HT}(-)(\boldsymbol{P})$ in the DR; and c-Fos $(+) / \mathrm{TH}(+)$ cells $(\boldsymbol{Q})$ and c-Fos $(+) / \mathrm{TH}(-)$ cells $(\boldsymbol{R})$ in the VTA/SNc of the animals that received injections of PBS (blue, $N=6$ ) or DHK (red, $N=7$ ) to the LHb. ${ }^{*} p<0.05$ (two-tailed Mann-Whitney $U$ test). ${ }^{* *} p<0.01$ (two-tailed Mann-Whitney $U$ test). Error bars indicate SEM. Scale bars: $\boldsymbol{A}$ (applies to $\boldsymbol{B}-\boldsymbol{J}$ ), $200 \mu \mathrm{m} ; \boldsymbol{C}$, inset (applies to $\boldsymbol{D}-\boldsymbol{E}, \boldsymbol{H}-\boldsymbol{J}$ ), $10 \mu \mathrm{m}$.

observe significant differences in the other unit activity characteristics, such as the shape (Fig. $1 \mathrm{~J}, L$ ) and width (Fig. $1 N$; MannWhitney $U$ test, $U_{14,10}=58.0, p=0.501$ ) of spikes between groups, suggesting that DHK increases the firing rate of $\mathrm{LHb}$ neurons.

\section{Reduced c-Fos expression in the serotonergic and dopaminergic neurons in the brainstems of mice with hyperactivation of the habenula}

To observe a trans-synaptic effect of the increased firing activity in the LHb, we injected PBS or DHK into the LHb via iontophoresis under anesthesia and examined the expression of the immediate early gene c-Fos to investigate the influence of the intra-LHb injection of DHK on the activity of the habenular circuit. DHK increased the number of c-Fos-positive cells (Fig. $2 F, K$ ) compared with PBS (Fig. $2 A, K$; Mann-Whitney $U$ test, $U_{5,5}=0.0, p=0.0079$ ) in the LHb but not in the MHb. We also observed that DHK increased the number of c-Fos-expressing cells in the RMTg (Fig. 2G,L), which receives an axonal projection from the LHb (Jhou et al., 2009; Kaufling et al., 2009), compared with PBS (Fig. 2B, L; Mann-Whitney $U$ test, $U_{6,6}=0.0, p=0.0022$ ).

Previous studies have reported that GABAergic neurons in the RMTg project to the dopaminergic VTA/SNc and to the serotonergic raphe nuclei (Jhou et al., 2009; Kaufling et al., 2009). The results of double-labeling the neurons with c-Fos and the markers for serotonergic (serotonin [5-HT] in Fig. 2C,D, H,I) and dopaminergic neurons (tyrosine hydroxylase $[\mathrm{TH}]$ in Fig. 2E,J) indicated that the DHK group displayed a smaller number of c-Fos-positive cells in the serotonergic neurons of the MR (Fig. $2 C, H, M$; Mann-Whitney $U$ test, $\left.U_{5,5}=0.0, p=0.0119\right)$ and of the DR (Fig. 2D,I,O; Mann-Whitney $U$ test, $U_{6,6}=0.0, p=$ 0.005 ) and in the dopaminergic neurons of the VTA/SNc (Fig. $2 E, J, Q ;$ Mann-Whitney $U$ test, $\left.U_{5,7}=0.0, p=0.0025\right)$ compared with those numbers in the PBS group, suggesting decreased acti- vation of the dopaminergic and serotonergic neurons in the animals with hyperactivated habenular neurons. Intriguingly, we also observed that intra-LHb injection of DHK increased c-Fos expression in the nondopaminergic neurons in the VTA/SNc (Fig. $2 E, J, R$; Mann-Whitney $U$ test, $U_{5,7}=4.0, p=0.0303$ ), whereas this injection decreased c-Fos expression in the nonserotonergic neurons of the MR (Fig. 2C, H,N; Mann-Whitney $U$ test, $U_{5,5}=2.0, p=0.0317$ ) and of the DR (Fig. 2D, I,P; MannWhitney $U$ test, $U_{6,6}=0.0, p=0.0022$ ) compared with intra$\mathrm{LHb}$ injection of PBS.

These results suggested that GLT-1 inhibition activated LHb neurons and increased the excitability of their direct target of LHb efferents, such as GABAergic neurons in the RMTg, which project to the brainstem monoaminergic neurons.

\section{Acute and chronic GLT-1 inhibition exacerbated}

unconditioned immobility behavior in the tail suspension test Next, we examined despair behavior using the tail suspension test in animals with pharmacological GLT-1 inhibition in the habenula to investigate the hypothesis that a hyperactivated habenula leads to a depressive-like phenotype (Fig. 3A). Bilateral LHb activation was induced via PBS (Fig. 3B) or DHK (Fig. 3C) injection under head-restrained awake conditions $30 \mathrm{~min}$ before the behavioral test. The tail suspension test revealed that animals with acute $\mathrm{LHb}$ activation by DHK injection displayed longer immobility duration (Fig. $3 D$, red; Mann-Whitney $U$ test, $U_{9,5}=5.0$, $p=0.0190)$ and shorter latency to the first immobility episode (Fig. 3E, red; Mann-Whitney $U$ test, $U_{9,5}=5.0, p=0.0190$ ) compared with mice with PBS injection (Fig. $3 D$, E, blue).

The duration of major depressive episodes varies in humans; however, the median duration of a major depressive episode has been reported to be 24.3 weeks in the United States (Solomon et al., 1997), indicating that the alterations in neural activity that are responsible for these symptoms are likely to be chronic. To ad- 

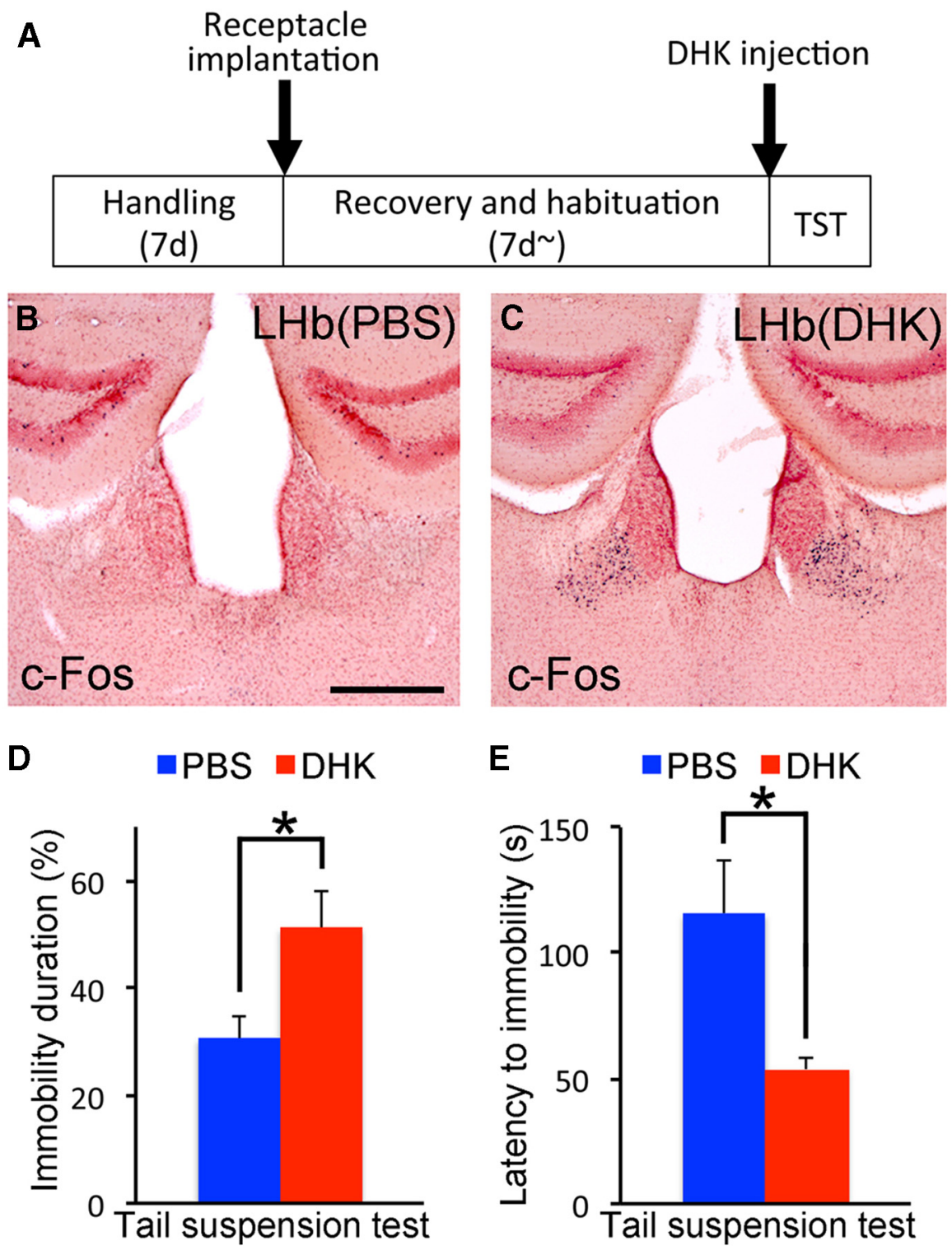

Figure 3. Acute inhibition of GLT-1 activity in habenular astrocytes exacerbates despair behavior in the tail suspension test. A, A schematic diagram showing the experimental design. After implantation of the receptacle for head restraint and recovery, DHK was bilaterally injected into the LHb via stereotaxic injection under awake conditions 30 min before the tail suspension test (TST). $B, C$, Coronal sections showing C-Fos expression (black) in the LHb after injections of PBS (B) or DHK (C). Sections were counterstained with neutral red. D, E, Bar graphs showing the mean immobility duration $(\boldsymbol{D})$ and the mean latency to the first immobility episode $(\boldsymbol{E})$ of the animals injected with PBS (blue, $N=9$ ) or with DHK (red, $N=5$ ) in the tail suspension test. ${ }^{*} p<0.05$ (two-tailed Mann-Whitney $U$ test). Error bars indicate SEM. Scale bars: $\boldsymbol{B}$ (applies to $\boldsymbol{C}$, $400 \mu \mathrm{m}$.

dress whether prolonged inhibition of GLT-1 activity leads to depressive-like behaviors, we generated conditional knock-out mice lacking the GLT-1 gene specifically in the habenula. We injected AAVs expressing EGFP or the EGFP-Cre fusion protein under the control of the GFAP promoter (Gfa104) into floxed GLT-1 mice (GLT-1 $1^{\text {flox/flox }}$ ), in which exon 4 , which encodes the transmembrane domain of GLT-1, was flanked by two loxP elements (Fig. 4A). The injection of AAVs-expressing EGFP-Cre (Hb-GLT-1 cKO in Fig. $4 E-G$ ), but not EGFP only (Hb-control in Fig. $4 B-D$ ), into the habenula of GLT- $1^{\text {flox/flox }}$ mice resulted in the complete disappearance of the GLT-1 protein in the LHb 4 weeks later (Fig. 4C,F, brackets).

To determine the effect of GLT-1 deletion in the astrocytes on the activity of LHb neurons, we recorded single-unit activity in $\mathrm{LHb}$ neurons in the Hb-control and Hb-GLT-1 cKO mice. These analyses revealed that Hb-GLT-1 cKO mice displayed higher fir- ing rates (Fig. $4 J, L$; Mann-Whitney $U$ test, $U_{51,46}=580.5, p=$ $1.11 \times 10^{-5}$ ) compared with the firing rates of $\mathrm{Hb}$-control mice (Fig. $4 H, L$ ), without significant differences in the other characteristics of the unit activity, such as the shape (Fig. $4 I, K$ ) and width (Fig. 4M; Mann-Whitney $U$ test, $U_{51,46}=951.0, p=0.110$ ) of spikes between groups. These results suggested that chronic GLT-1 deletion increased the neuronal activity in LHb.

The tail suspension test revealed that Hb-GLT-1 cKO mice exhibited longer immobility duration (Fig. $4 N$, red; $F_{(3,45)}=$ 11.223, Tukey's post hoc test, $p=0.0226$ ) and shorter latency to the first immobility episode (Fig. $4 O$, red; $F_{(3,45)}=15.298$, Tukey's post hoc test, $p=0.0404$ ) compared with Hb-control mice (Fig. $4 \mathrm{~N}, \mathrm{O}$, blue). Interestingly, the administration of the selective serotonin reuptake inhibitor fluoxetine, but not vehicle, improved the immobility duration (Fig. $4 N ; F_{(3,45)}=11.223$, Tukey's post hoc test, $p=6.12 \times 10^{-5}$ ) and latency to immobility 
A
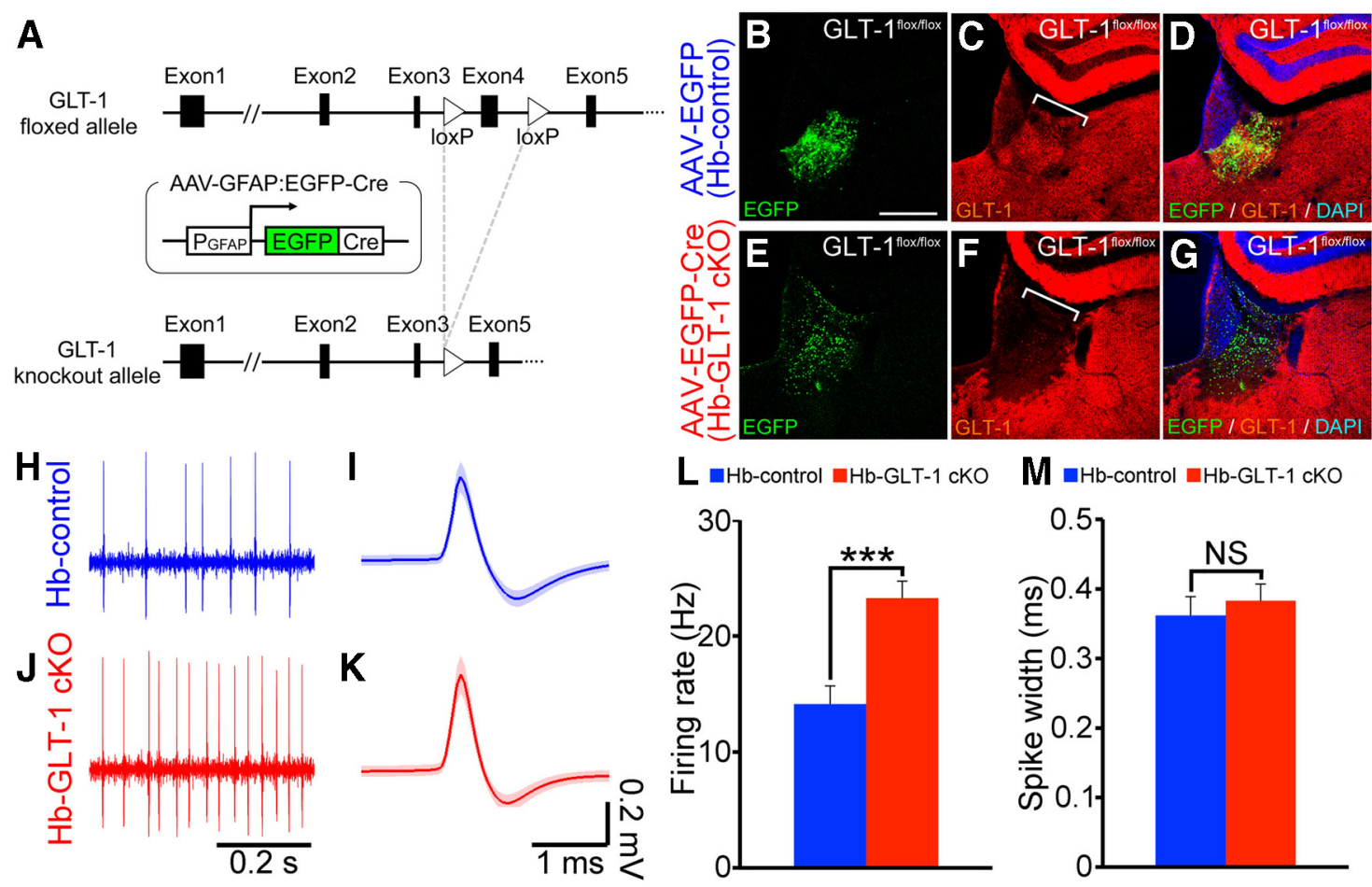

$\mathbf{L}$ घhb-control $\mathbf{m H b}_{\mathrm{H}} \mathrm{GLT}-1 \mathrm{cKO}$

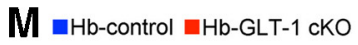
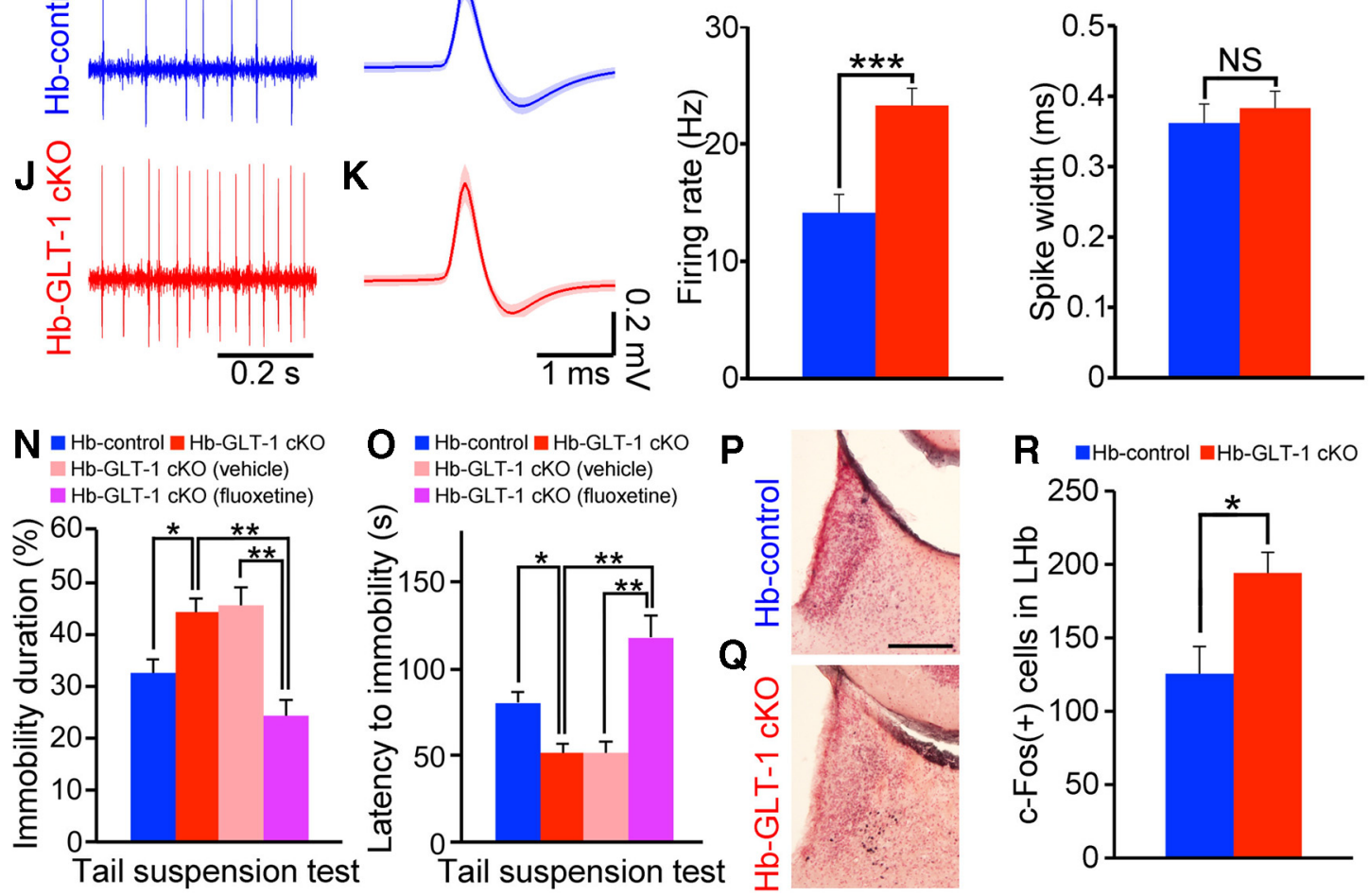

Figure 4. Virus-mediated deletion of the GLT-1 gene in habenular astrocytes elicited depressive-like behaviors in the tail suspension test, with increased neuronal excitability. $A$, A schematic diagram showing the strategy for GLT-1 gene deletion in cells transduced with an AAV vector expressing an EGFP-Cre fusion protein under the control of a GFAP promoter (Pgfap). $\boldsymbol{B}$ - $\mathbf{G}$, Coronal sections of the LHb of GLT- 1 flox/flox mice with the injection of an EGFP-expressing vector (Hb-control in $\boldsymbol{B}-\boldsymbol{D}$ ) or EGFP-Cre-expressing vector (Hb-GLT-1 cKO in E-G) showing the expression of GLT-1 $(\boldsymbol{C}, \boldsymbol{D}, \boldsymbol{F}, \boldsymbol{G}$, red) and EGFP ( $\boldsymbol{B}, \boldsymbol{D}, \boldsymbol{E}, \boldsymbol{G}$, green). Sections were counterstained with DAPI ( $\boldsymbol{D}, \boldsymbol{G}$, blue). $\boldsymbol{C}, \boldsymbol{F}$, White brackets indicate the $L H b . \boldsymbol{H}, \boldsymbol{J}$, Representative activities of the $L H b$ neurons in the $\mathrm{Hb}$-control $(\boldsymbol{H})$ and $\mathrm{Hb}$-GLT-1 $\mathrm{CKO}$ mice $(\boldsymbol{J})$. $\boldsymbol{I}, \boldsymbol{K}$, Average spike shape of the neurons shown in $\boldsymbol{H}$ (blue solid line in $\boldsymbol{I}$ ) and $\boldsymbol{J}$ (red solid line in $\boldsymbol{K}$ ). Shaded areas represent $S E M$. $\boldsymbol{L}, \boldsymbol{M}, \boldsymbol{B}$ Bar graphs represent the mean firing rate $(\boldsymbol{L})$ and mean spike width $(\boldsymbol{M})$ of the spikes recorded from the $\mathrm{Hb}$-control (blue, $N=51$ ) and $\mathrm{Hb}$-GLT-1 cKO mice (red, $N=46)$. $N, \mathbf{0}$, Bar graphs showing the mean immobility duration $(\boldsymbol{N})$ and latency to the first immobility episode $(\mathbf{O})$ of the $\mathrm{Hb}$-control mice (blue, $N=12$ ), $\mathrm{Hb}$-GLT-1 cK0 mice without treatment (red, $N=16$ ), and Hb-GLT-1 cK0 mice with vehicle (pink, $N=10$ ) or fluoxetine (purple, $N=11$ ) treatment in the tail suspension test. $\boldsymbol{P}, \boldsymbol{Q}$, Coronal sections of the LHb of Hb-control $(\boldsymbol{P})$ and Hb-GLT-1 CKO ( $\boldsymbol{Q}$ ) mice showing c-Fos expression (black). Sections were counterstained with neutral red. $\boldsymbol{R}$, Bar graph represents the mean number of c-Fos-expressing cells in the LHb of Hb-control (blue, $N=8$ ) and Hb-GLT-1 cKO (red, $N=6$ ) mice. ${ }^{*} p<0.05$ (Tukey's post hoc test for multiple comparisons following one-way ANOVA for four group data and two-tailed Mann-Whitney Utest for two group data). ${ }^{* *} p<0.01$ (Tukey's post hoctest for multiple comparisons following one-way ANOVA). ${ }^{* *} p<0.0001$ (two-tailed Mann-Whitney U test). NS, Not significant. Error bars indicate SEM. Scale bars: $\boldsymbol{B}$ (applies to $\boldsymbol{C}-\boldsymbol{G}$ ), $200 \mu \mathrm{m}$; and $\boldsymbol{P}$ (applies to Q), $200 \mu \mathrm{m}$.

(Fig. $4 O ; F_{(3,45)}=15.298$, Tukey's post hoc test, $p=1.10 \times 10^{-6}$ ) in $\mathrm{Hb}-\mathrm{GLT}-1 \mathrm{cKO}$ mice, suggesting that the observed depressivelike phenotype of $\mathrm{Hb}-\mathrm{GLT}-1 \mathrm{cKO}$ mice in the tail suspension test was mediated by excessive inhibition of the serotonergic systems.

Consistent with the effect of the pharmacological blockade of GLT-1, a larger number of c-Fos-expressing cells were observed in the LHb of Hb-GLT-1 cKO mice (Fig. $4 P, R$ ) than of Hbcontrol mice (Fig. 4Q, R; Mann-Whitney $U$ test, $U_{8,6}=7.0, p=$ $0.0330)$ after the tail suspension test.

Together, persistent GLT-1 inhibition increased excitability in the $\mathrm{LHb}$, resulting in the observed depressive-like behaviors in the tail suspension test.
Habenula-specific GLT-1 deletion elicited depressive-like phenotypes in conflict-based behavioral tests without affecting locomotor activity

Restraint-based and unconditioned tests, such as the tail suspension test, are useful for screening antidepressant drugs; however, the rapid effect of many antidepressants in these tests may not simulate the time course of clinical depression treatment, which typically requires $>14 \mathrm{~d}$ for the antidepressants to be effective (Berton and Nestler, 2006).

We tested whether GLT-1 deletion in the LHb affects depressive-like behaviors relevant to major depression in humans using novelty-suppressed feeding (Merali et al., 2003; Santarelli et al., 2003) and the social avoidance test (Berton et al., 
2006), which are conflict-based behavioral tests that are responsive to chronic, but not acute, antidepressant treatment.

In novelty-suppressed feeding, we measured the latency for the food-deprived animals to consume the food at the center of an unfamiliar arena. This analysis revealed that $\mathrm{Hb}$-GLT-1 cKO mice (Fig. 5A, red) fed later in a novel environment compared with $\mathrm{Hb}$-control mice (Fig. 5A, blue; Mann-Whitney $U$ test, $U_{15,15}=$ 57.0, $p=0.0225)$. This change could not be attributed to decreased locomotor activity in Hb-GLT-1 cKO mice because we observed no significant difference between groups in the total distance moved in the open-field test (Fig. 5B; MannWhitney $U$ test, $U_{9,11}=29.0, p=0.129$ ).

Recent studies have demonstrated that the susceptibility of the behavioral responses to chronic social defeat stress could be a useful measure of depressivelike behaviors and responses to chronic, but not acute, antidepressant treatment (Berton et al., 2006). Therefore, we addressed the influence of GLT-1 deletion on the susceptibility to chronic stress using this model. Nondefeated Hb-control and Hb-GLT-1 cKO mice displayed comparable behaviors in interactions with aggressors in the mesh cage during the social avoidance test (Fig. 5C, E, G; Mann-Whitney $U$ test, $\left.U_{9,10}=36.0, p=0.497\right)$. However, after the chronic social defeat stress, Hb-GLT-1 cKO mice approached the mesh cage less frequently (Fig. 5F, red) and displayed a lower interaction ratio (Fig. $5 \mathrm{H}$, red) than $\mathrm{Hb}$-control mice (Fig. $5 D, H$, blue; Mann-Whitney $U$ test, $\left.U_{11,10}=13.0, p=0.0076\right)$ during the social avoidance test, suggesting that Hb-GLT-1 cKO mice had increased susceptibility to chronic stress.

These analyses indicated that GLT-1 deletion in the LHb sensitized the animals and provoked a depressive-like phenotype in conflict-based behavioral tests that were reported to respond only to chronic antidepressant treatment, as in major depression in humans.

Hyperactivation of the habenula led to the disinhibition of REM sleep

Sleep disturbance is a core symptom of depression and is found in $90 \%$ of patients with depression (Riemann et al., 2001). Previous studies have repeatedly reported that depression is associated with longer REM sleep periods and with a shorter latency to the onset of REM sleep, which suggests that altered REM sleep is an endophenotype of depression (Hasler et al., 2004; Gottesmann and
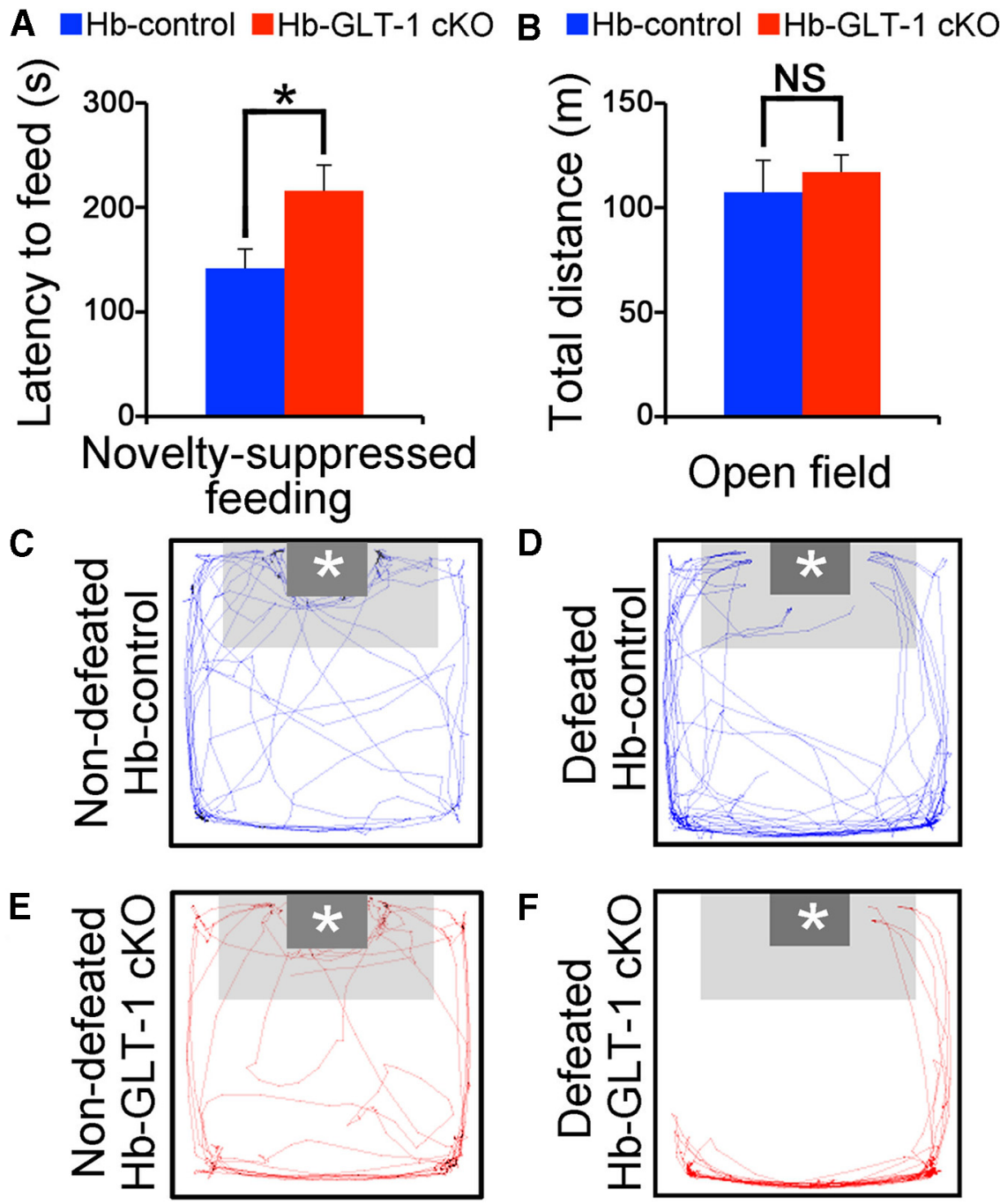

G $\square \mathrm{Hb}$-control $\square \mathrm{Hb}-\mathrm{GLT}-1 \mathrm{cKO} \mathbf{H}$

Hb-control $\square \mathrm{Hb}-\mathrm{GLT}-1 \mathrm{cKO}$
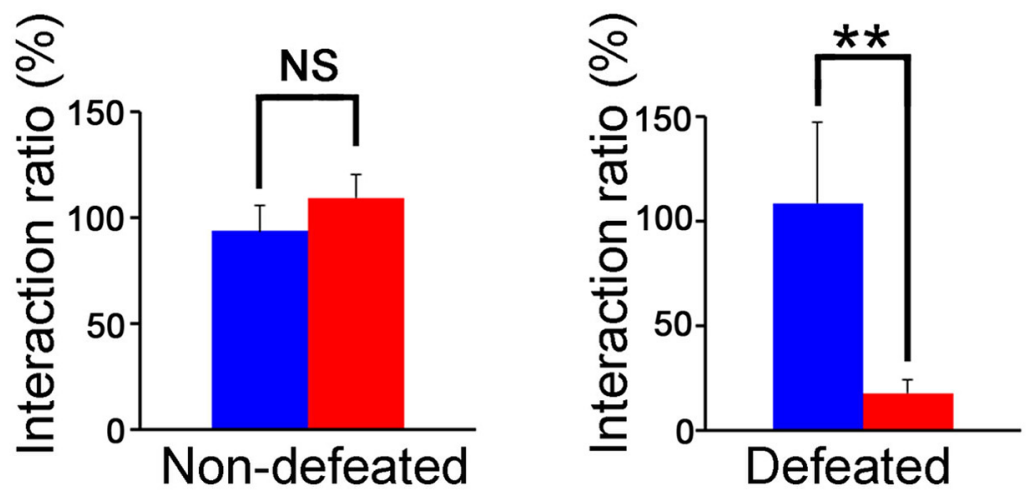

Figure 5. Habenula-specific GLT-1 deletion leads to depressive-like behaviors under stress without affecting locomotion. $\boldsymbol{A}, \boldsymbol{B}$, Bar graphs represent the mean latency to feeding in novelty-suppressed feeding of $\mathrm{Hb}$-control (blue, $N=15)$ and $\mathrm{Hb}-\mathrm{GLT}-1 \mathrm{cKO}$ mice (red, $N=15)(\boldsymbol{A})$ and the total distance traveled during the open-field test of the $\mathrm{Hb}$-control (blue, $N=9)$ and Hb-GLT-1 cKO mice (red, $N=11)(\boldsymbol{B}) . \boldsymbol{C}-\boldsymbol{F}$, Representative traces of movement during the social avoidance test in the presence of aggressors (white asterisks) of the $\mathrm{Hb}$-control $(\boldsymbol{C}, \boldsymbol{D}$, blue lines) and $\mathrm{Hb}$-GLT-1 CKO mice $(\boldsymbol{E}, \boldsymbol{F}$, red lines) after nondefeated $(\boldsymbol{C}, \boldsymbol{E})$ and defeated $(\boldsymbol{D}, \boldsymbol{F})$ treatments. Dark and light gray areas represent the mesh cage and interaction zone, respectively. $\boldsymbol{G}, \boldsymbol{H}$, Bar graphs represent the mean interaction ratio during the social avoidance test after nondefeated $(\boldsymbol{G})$ and defeated $(\boldsymbol{H})$ treatments of the $\mathrm{Hb}$-control (blue, $N=9$ and 11 for nondefeated and defeated groups, respectively) and Hb-GLT- 1 cKO mice (red, $N=10$ for nondefeated and defeated groups). ${ }^{*} p<0.05$ (two-tailed Mann-Whitney $U$ test). ${ }^{* *} p<0.01$ (two-tailed Mann-Whitney $U$ test). Error bars indicate SEM. NS, not significant. 
A
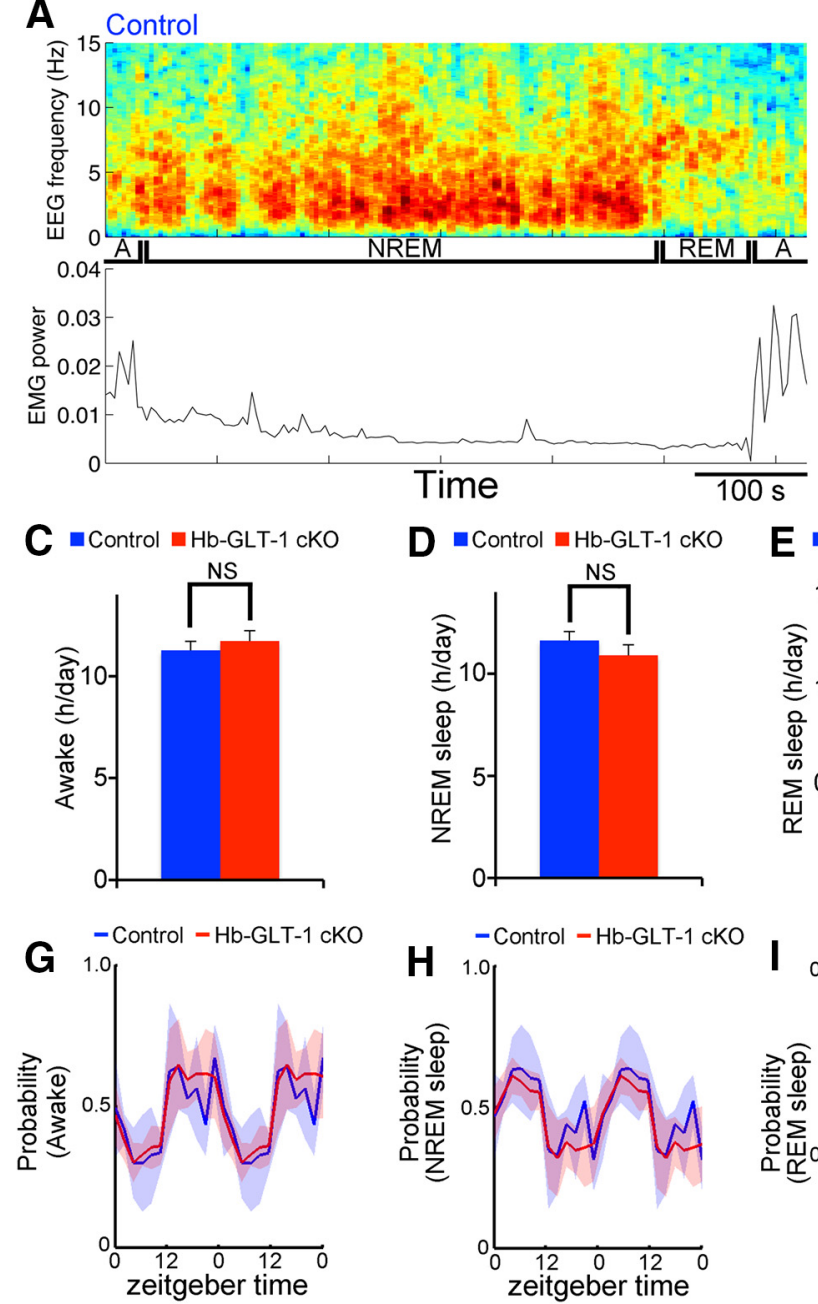

E

\section{B}
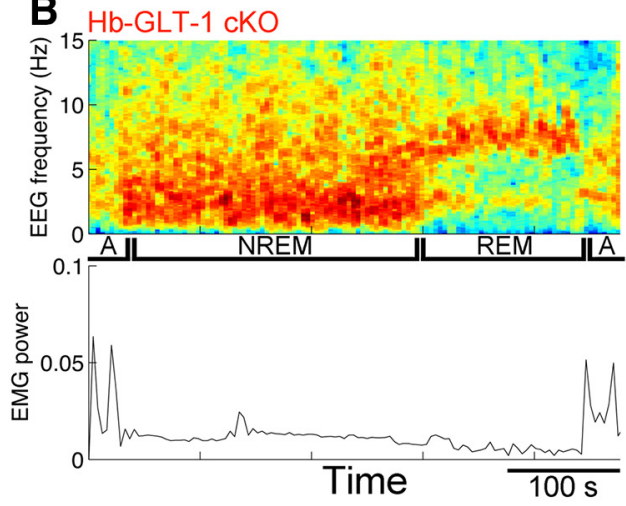

$\square$ Control $=\mathrm{Hb}-\mathrm{GLT}-1 \mathrm{cKO}$

F Control $\square \mathrm{Hb}-\mathrm{GLT}-1 \mathrm{cKO}$
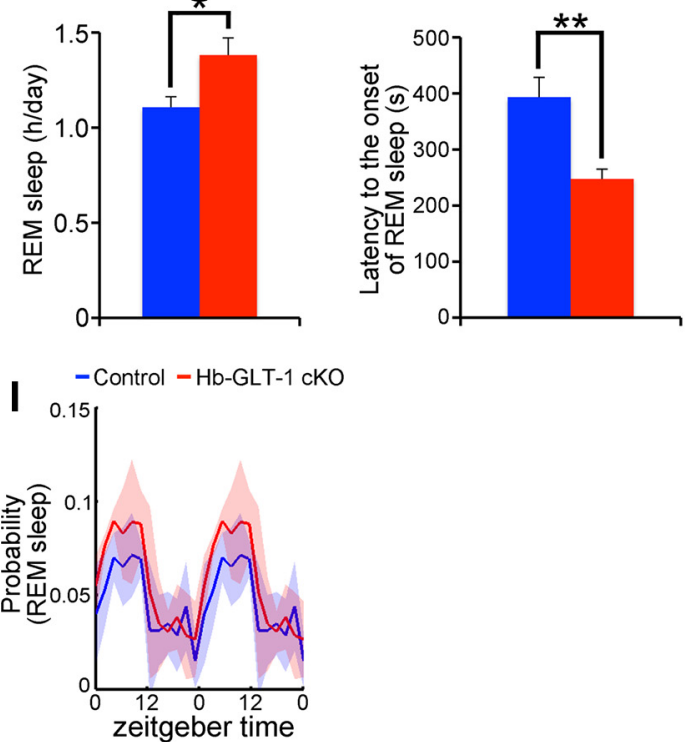

Figure 6. Disinhibition of REM sleep by GLT-1 deletion in the habenular astrocytes. $\boldsymbol{A}, \boldsymbol{B}$, Representative sleep pattern in $\mathrm{Hb}$-control $(\boldsymbol{A})$ and $\mathrm{Hb}$-GLT-1 $\mathrm{CKO}(\boldsymbol{B})$ mice, which is classified into the awake $(\boldsymbol{A})$, non-REM (NREM), and REM sleep periods according to the spectrogram of EEG (top) and EMG power (bottom). $\boldsymbol{C}-\boldsymbol{F}$, Bar graphs represent the mean duration spent awake $(\boldsymbol{C})$, in NREM sleep $(\boldsymbol{D})$, and in REM sleep $(\boldsymbol{E})$ and the mean latency to the onset of REM sleep $(\boldsymbol{F})$ in Hb-control (blue, $N=7)$ or Hb-GLT-1 cKO (red, $N=6)$ mice. $\mathbf{G}-\mathbf{I}$, Line plots represent the mean probability for being awake $(\boldsymbol{G})$, in NREM sleep $(\boldsymbol{H})$, and in REM sleep $(\boldsymbol{I})$ along Zeitgeber time in $\mathrm{Hb}$-control (blue, $N=7)$ and $\mathrm{Hb}-\mathrm{GLT}-1 \mathrm{cKO}(\mathrm{red}, \mathrm{N}=6)$ mice. The probability for each stage category was calculated for each $2 \mathrm{~h}$ bin. ${ }^{*} p<0.05$ (two-tailed Mann-Whitney U test). ${ }^{* *} p<0.01$ (two-tailed Mann-Whitney U test). $\boldsymbol{C}-\boldsymbol{F}$, Error bars indicate SEM. G-I, Shaded areas represent SEM. NS, not significant.

Gottesman, 2007; Modell and Lauer, 2007; Steiger and Kimura, 2010). The molecular mechanisms responsible for the alteration of REM sleep remain elusive possibly because of the lack of analysis in model animals amenable to genetic manipulations.

Recently, we found that synchronous activity in the LHb is essential for maintaining REM sleep (Aizawa et al., 2013b). Therefore, we hypothesized that the animals with a hyperactivated habenula, such as Hb-GLT-1 cKO mice, might show REM sleep deficits reminiscent of the sleep disturbances observed in depression. We measured EEGs (Fig. 6A, $B$, top) and EMGs (Fig. $6 A, B$, bottom) to classify the recording periods as awake, REM sleep, and non-REM sleep periods over $48 \mathrm{~h}$.

The sleep stage analysis revealed that Hb-GLT-1 cKO mice spent more time in REM sleep (Fig. 6E, red; Mann-Whitney $U$ test, $U_{7,6}=7.0, p=0.0455$ ) but not awake (Fig. $6 C$, red; MannWhitney $U$ test, $U_{7,6}=15.0, p=0.391$ ) or in non-REM sleep (Fig. $6 D$, red; Mann-Whitney $U$ test, $\left.U_{7,6}=13.0, p=0.253\right)$ compared with $\mathrm{Hb}$-control mice (Fig. $6 C, D, E$, blue). Intriguingly, we observed that the latency to the onset of REM sleep in each sleep episode was significantly shorter in Hb-GLT-1 cKO mice (Fig. 6F, red; Mann-Whitney $U$ test, $U_{7,6}=6.0, p=0.00664$ ) than in $\mathrm{Hb}$-control mice (Fig. $6 F$, blue). We performed a circular analysis to determine whether these sleep-awake data displayed a circadian rhythm with unimodal distribution of the each sleep stages (Fisher, 1993). Analyses of the sleep stages revealed that both the $\mathrm{Hb}$-control and $\mathrm{Hb}-\mathrm{GLT}-1 \mathrm{cKO}$ mice displayed significantly unimodal distributions for all three sleep stages, including awake (Fig. $6 G$; Rayleigh's test, $Z_{69315}=$ 1544.5, $p=0$ for Hb-control mice; $Z_{61793}=1925.7, p=0$ for Hb-GLT-1 cKO mice), non-REM sleep (Fig. $6 H$; Rayleigh's test, $Z_{71529}=1084.0, p=0$ for Hb-control mice; $Z_{57488}=$ $1367.0, p=0$ for Hb-GLT-1 cKO mice), and REM sleep (Fig. $6 I$; Rayleigh's test, $Z_{6818}=370.0, p=2.14 \times 10^{-161}$ for Hbcontrol mice; $Z_{7291}=608.4, p=5.74 \times 10^{-265}$ for Hb-GLT-1 cKO mice), suggesting that Hb-control and Hb-GLT-1 cKO mice exhibited a typical light-entrained circadian rhythm of sleep and wakefulness, with longer durations of REM and nonREM sleep during the light period, indicating that the disinhibited REM sleep in Hb-GLT-1 cKO mice was not likely the result of impaired circadian rhythms. 


\section{Discussion}

The present study demonstrating that Hb-GLT-1 cKO mice exhibited multiple depressive-like behaviors under stress provided the first evidence that glial dysfunction is sufficient to elicit pathological activation of the $\mathrm{LHb}$, resulting in depressive-like phenotypes, such as frequent despair-like and avoidance behaviors under stress and enhanced REM sleep. Below, we discuss how the reduced GLT-1 activity in the habenula leads to behavioral deficits that are reminiscent of depressive symptoms.

\section{Role of astrocyte dysfunction in the hyperactivation of the habenula}

Growing evidence has indicated that glial cell dysfunction is involved in the pathophysiology of depression (Rajkowska and Miguel-Hidalgo, 2007). However, the lack of useful tools for gene modification in glial cells complicates the delineation of their roles in the specific neural pathways relevant to the core symptoms of depression, such as reduced motivation, anhedonia, and sleep disturbance.

In the current study, the combination of a novel viral vector expressing Cre recombinase predominantly in astrocytes with GLT- $1^{\text {flox/flox }}$ mice allowed us to identify the role of GLT-1 in depressive-like behaviors and sleep in mice. Because of the specificity of GLT-1 expression to the astrocytes in LHb, the EGFPCre-expressing AAV most likely did not affect the neuronal activity via GLT-1 gene deletion in neurons. We did not rely on the specificity of the human GFAP promoter Gfa104, which was used in the AAV injections to target the astrocytes, because previous studies reported that the Gfa104 promoter drove reporter gene expression in the neurons (to a lesser extent) and astrocytes (Ortinski et al., 2010). However, the AAV harboring Gfa104 promoter remained a useful tool to transduce the gene of interest to the astrocytes because of the much higher specificity of the transduction to the astrocytes than to the neurons. Thus, the combination of AAV vectors driving Cre recombinase preferentially in the astrocytes and the specificity of GLT-1 expression to the astrocytes in the LHb allowed us to perform astrocyte-specific gene manipulation. Using this technology, we can examine the behavioral changes in animals with genetically manipulated astrocytes in specific neural pathways and gain greater insight regarding glial pathology in psychiatric disorders.

Despite the low endogenous expression of GFAP protein in the LHb compared with the MHb, we observed successful expression of the AAV transgene using the Gfa104 promoter in the LHb astrocytes. The Gfa104 promoter is derived from a combination of multiple regulatory elements within the human GFAP promoter (Lee et al., 2008). When considering the synthetic nature of the Gfa104 promoter and the species difference, the Gfa104 promoter might drive reporter expression in a broader population of murine astrocytes compared with those expressing GFAP endogenously.

Recent studies have reported reduced GLT-1 in patients with major depression (Choudary et al., 2005; Medina et al., 2013; Oh et al., 2014) and in rat models of depression (Zink et al., 2010), suggesting that reduced glial glutamate transport activity underlies depression. In support of this view, ceftriaxone, which enhances the transcriptional activity of GLT-1 (Rothstein et al., 2005), has antidepressant effects in animal models (Mineur et al., 2007). Interestingly, a study recently reported a significant association between the allelic variability in GLT-1 (SLC1A2 in human) and suicidal attempts (Murphy et al., 2011), suggesting that GLT-1 may influence susceptibility to suicidal attempts, which frequently occurs in the patients with depression (Mann et al.,
1999). Our results provided direct evidence that the pharmacological and genetic inhibition of glial activity, such as glutamate transport, is sufficient to cause multiple depressive-like behaviors.

For neuronal signaling that modifies neuronal excitability in the $\mathrm{LHb}$, a recent report has demonstrated that overexpression of the calcium/calmodulin-dependent kinase $\beta$ CaMKII increased synaptic and spike output in mouse LHb neurons and elicited depression-like behaviors (Li et al., 2013). However, the mechanisms of $\beta$ CaMKII upregulation remain unknown. Neurons in the $\mathrm{LHb}$ were activated when the animals were presented with stressful and aversive stimuli (Matsumoto and Hikosaka, 2009). Because treatment with glucocorticoids, which are increased by chronic stress, leads to reduced GLT-1 mRNA transcription (Gourley et al., 2012), alterations in glutamate transporter activity in LHb astrocytes may upregulate $\beta$ CaMKII expression by an increase in the firing rate of LHb neurons, resulting in the expression of depressive-like behaviors.

\section{Regulation of the monoaminergic systems by increasing the firing activity of the $\mathrm{LHb}$ during behaviors under stress} According to the projection of LHb neurons to the RMTg and the dense GABAergic inhibitory inputs from the RMTg to the raphe nuclei and to the VTA/SNc (Jhou et al., 2009; Kaufling et al., 2009), activation of RMTg may have led to the reduced c-Fos expression observed in the monoaminergic neurons after intra$\mathrm{LHb}$ injection of DHK. In contrast, GABAergic neurons constitute the majority of the nondopaminergic populations in the VTA/SNc (Nair-Roberts et al., 2008). Because LHb axons projecting directly to the VTA/SNc are glutamatergic (Geisler et al., 2007; Aizawa et al., 2012), increased c-Fos expression in nondopaminergic neurons due to intra-LHb DHK is consistent with the idea that the excitatory glutamatergic inputs from the hyperactivated LHb activated GABAergic neurons in the VTA/SNc, which, in turn, led to reduced c-Fos expression in the dopaminergic neurons. Thus, these direct and indirect inputs to the VTA/SNc may act in a synergistic way to affect the activity of the midbrain dopaminergic neurons. Nonserotonergic neurons in the raphe nuclei consist of glutamatergic and GABAergic neurons, as well as a variety of peptidergic neurons, displaying heterogeneity in the cell types (Fu et al., 2010; Hioki et al., 2010). The identification of the specific cell types in nonserotonergic neurons under the influence of the LHb inputs will clarify the role of the LHb in the modulation of the serotonergic system.

Behaviors, such as social avoidance of conflicts and immobility under acute stress, are recognized as passive coping behaviors in response to a stressful environment (Coppens et al., 2010) and are frequently observed in depression (Taylor and Stanton, 2007). Accumulating evidence suggests that the serotonergic dorsal raphe plays a critical role in modulating stress coping behaviors (Franklin et al., 2012). Indeed, two independent studies consistently provided evidence that the serotonergic neurons in the dorsal raphe displayed reduced neural activity, which was associated with passive coping behaviors after repeated exposure to stress (Bambico et al., 2009; Espallergues et al., 2012). In contrast, impairments in dopaminergic transmission also suppress motor behavior (Wise, 2004), and repetitive stressors, such as aversive stimuli, sensitize LHb neurons and increase baseline activity, which may lead to persistent reductions in the firing activity of midbrain dopaminergic neurons and decreased motor behavior (Hikosaka, 2010). In support of a role of dopamine in depressive-like behavior, a recent study reported that optogenetic inhibition of the midbrain dopaminergic neurons exaggerated 
immobile behavior with less struggling under tail suspension (Tye et al., 2013). Because GLT-1 inhibition in the LHb reduced c-Fos expression in the dopaminergic and serotonergic neurons in the brainstem, activated LHb may have forced the animals to shift toward the passive coping strategy in multiple behaviors under stress by altering the serotonergic and dopaminergic levels in the brains of Hb-GLT-1 cKO mice.

\section{Hyperactivation of the habenula as a link between behavioral deficits and sleep disturbance in depression}

Serotonin has been implicated in the transition to REM sleep, according to the evidence that serotonergic neurons in the raphe cease to fire during REM sleep (Jouvet, 1969) and that inhibition of serotonergic dorsal raphe neurons increases REM sleep production (Portas et al., 1996; Nitz and Siegel, 1997). Considering the regulatory role of the $\mathrm{LHb}$ in the central serotonergic activity as described above, the LHb is in a strategic position that affects REM sleep through modulating neuronal activity in the serotonergic system. Indeed, we recently found that the LHb plays a role in maintaining REM sleep (Aizawa et al., 2013b).

Despite the coincidence of behavioral changes and sleep disturbance in depression, whether sleep disturbance is a cause or an outcome of the behavioral changes remains unanswered. The induction of depressive-like behaviors and enhanced REM sleep by hyperactivation of the habenula in our study support an alternative hypothesis that common dysfunction in a specific pathway may modulate the activities in diffuse serotonergic and dopaminergic systems, which act on multiple neural systems, each of which is responsible for individual behavioral and sleep deficits in depression (Aizawa et al., 2013a).

A recent study reported that DBS of the axonal bundles projecting to the habenula led to the amelioration of the symptoms in the patients with treatment-resistant depression (Sartorius et al., 2010). It is assumed that the effect of DBS in the habenular circuit in depressive patients may result from functional inhibition of the habenula because of the high frequency of afferent axons (Kiening and Sartorius, 2013). This hypothesis is based on the observation that the DBS protocol used in patients effectively reduces excitatory synaptic transmission in the rat LHb (Li et al., 2011). Because we showed that hyperactivity in the habenula disinhibited REM sleep in animals, it would be interesting to examine whether DBS of the habenula ameliorates REM sleep dysregulation in Hb-GLT-1 cKO.

\section{References}

Aizawa H, Kobayashi M, Tanaka S, Fukai T, Okamoto H (2012) Molecular characterization of the subnuclei in rat habenula. J Comp Neurol 520: 4051-4066. CrossRef Medline

Aizawa H, Cui W, Tanaka K, Okamoto H (2013a) Hyperactivation of the habenula as a link between depression and sleep disturbance. Front Hum Neurosci 7:826. CrossRef Medline

Aizawa H, Yanagihara S, Kobayashi M, Niisato K, Takekawa T, Harukuni R, McHugh TJ, Fukai T, Isomura Y, Okamoto H (2013b) The synchronous activity of lateral habenular neurons is essential for regulating hippocampal theta oscillation. J Neurosci 33:8909-8921. CrossRef Medline

Arriza JL, Fairman WA, Wadiche JI, Murdoch GH, Kavanaugh MP, Amara SG (1994) Functional comparisons of three glutamate transporter subtypes cloned from human motor cortex. J Neurosci 14:5559-5569. Medline

Bambico FR, Nguyen NT, Gobbi G (2009) Decline in serotonergic firing activity and desensitization of 5-HT1A autoreceptors after chronic unpredictable stress. Eur Neuropsychopharmacol 19:215-228. CrossRef Medline

Berens P (2009) CircStat: a MATLAB Toolbox for Circular Statistics. J Stat Softw 31:1-21.

Berton O, Nestler EJ (2006) New approaches to antidepressant drug discov- ery: beyond monoamines. Nat Rev Neurosci 7:137-151. CrossRef Medline

Berton O, McClung CA, Dileone RJ, Krishnan V, Renthal W, Russo SJ, Graham D, Tsankova NM, Bolanos CA, Rios M, Monteggia LM, Self DW, Nestler EJ (2006) Essential role of BDNF in the mesolimbic dopamine pathway in social defeat stress. Science 311:864-868. CrossRef Medline

Chaudhry FA, Lehre KP, van Lookeren Campagne M, Ottersen OP, Danbolt NC, Storm-Mathisen J (1995) Glutamate transporters in glial plasma membranes: highly differentiated localizations revealed by quantitative ultrastructural immunocytochemistry. Neuron 15:711-720. CrossRef Medline

Chen W, Mahadomrongkul V, Berger UV, Bassan M, DeSilva T, Tanaka K, Irwin N, Aoki C, Rosenberg PA (2004) The glutamate transporter GLT1a is expressed in excitatory axon terminals of mature hippocampal neurons. J Neurosci 24:1136-1148. CrossRef Medline

Choudary PV, Molnar M, Evans SJ, Tomita H, Li JZ, Vawter MP, Myers RM, Bunney WE Jr, Akil H, Watson SJ, Jones EG (2005) Altered cortical glutamatergic and GABAergic signal transmission with glial involvement in depression. Proc Natl Acad Sci U S A 102:15653-15658. CrossRef Medline

Coppens CM, de Boer SF, Koolhaas JM (2010) Coping styles and behavioural flexibility: towards underlying mechanisms. Philos Trans R Soc Lond B Biol Sci 365:4021-4028. CrossRef Medline

Danbolt NC, Storm-Mathisen J, Kanner BI (1992) An $[\mathrm{Na}++\mathrm{K}+]$ coupled L-glutamate transporter purified from rat brain is located in glial cell processes. Neuroscience 51:295-310. CrossRef Medline

Debus E, Weber K, Osborn M (1983) Monoclonal antibodies specific for glial fibrillary acidic (GFA) protein and for each of the neurofilament triplet polypeptides. Differentiation 25:193-203. Medline

Espallergues J, Teegarden SL, Veerakumar A, Boulden J, Challis C, Jochems J, Chan M, Petersen T, Deneris E, Matthias P, Hahn CG, Lucki I, Beck SG, Berton O (2012) HDAC6 regulates glucocorticoid receptor signaling in serotonin pathways with critical impact on stress resilience. J Neurosci 32:4400-4416. CrossRef Medline

Fields RD, Stevens-Graham B (2002) New insights into neuron-glia communication. Science 298:556-562. CrossRef Medline

Fisher N (1993) Statistical analysis of circular data. Cambridge: Cambridge UP.

Franklin TB, Saab BJ, Mansuy IM (2012) Neural mechanisms of stress resilience and vulnerability. Neuron 75:747-761. CrossRef Medline

Fu W, Le Maître E, Fabre V, Bernard JF, David Xu ZQ, Hökfelt T (2010) Chemical neuroanatomy of the dorsal raphe nucleus and adjacent structures of the mouse brain. J Comp Neurol 518:3464-3494. CrossRef Medline

Geisler S, Derst C, Veh RW, Zahm DS (2007) Glutamatergic afferents of the ventral tegmental area in the rat. J Neurosci 27:5730-5743. CrossRef Medline

Gottesmann C, Gottesman I (2007) The neurobiological characteristics of rapid eye movement (REM) sleep are candidate endophenotypes of depression, schizophrenia, mental retardation and dementia. Prog Neurobiol 81:237-250. CrossRef Medline

Gourley SL, Swanson AM, Jacobs AM, Howell JL, Mo M, Dileone RJ, Koleske AJ, Taylor JR (2012) Action control is mediated by prefrontal BDNF and glucocorticoid receptor binding. Proc Natl Acad Sci U S A 109:2071420719. CrossRef Medline

Haan EA, Boss BD, Cowan WM (1982) Production and characterization of monoclonal antibodies against the "brain-specific" proteins 14-3-2 and S-100. Proc Natl Acad Sci U S A 79:7585-7589. CrossRef Medline

Hasler G, Drevets WC, Manji HK, Charney DS (2004) Discovering endophenotypes for major depression. Neuropsychopharmacology 29:17651781. CrossRef Medline

Hazan L, Zugaro M, Buzsáki G (2006) Klusters, NeuroScope, NDManager: a free software suite for neurophysiological data processing and visualization. J Neurosci Methods 155:207-216. CrossRef Medline

Hikosaka O (2010) The habenula: from stress evasion to value-based decision-making. Nat Rev Neurosci 11:503-513. CrossRef Medline

Hioki H, Nakamura H, Ma YF, Konno M, Hayakawa T, Nakamura KC, Fujiyama F, Kaneko T (2010) Vesicular glutamate transporter 3-expressing nonserotonergic projection neurons constitute a subregion in the rat midbrain raphe nuclei. J Comp Neurol 518:668-686. CrossRef Medline

Ishiwata A, Mimuro J, Mizukami H, Kashiwakura Y, Takano K, Ohmori T, Madoiwa S, Ozawa K, Sakata Y (2009) Liver-restricted expression of the 
canine factor VIII gene facilitates prevention of inhibitor formation in factor VIII-deficient mice. J Gene Med 11:1020-1029. CrossRef Medline

Isomura Y, Harukuni R, Takekawa T, Aizawa H, Fukai T (2009) Microcircuitry coordination of cortical motor information in self-initiation of voluntary movements. Nat Neurosci 12:1586-1593. CrossRef Medline

Jhou TC, Geisler S, Marinelli M, Degarmo BA, Zahm DS (2009) The mesopontine rostromedial tegmental nucleus: a structure targeted by the lateral habenula that projects to the ventral tegmental area of Tsai and substantia nigra compacta. J Comp Neurol 513:566-596. CrossRef Medline

Ji H, Shepard PD (2007) Lateral habenula stimulation inhibits rat midbrain dopamine neurons through a GABA(A) receptor-mediated mechanism. J Neurosci 27:6923-6930. CrossRef Medline

Jouvet M (1969) Biogenic amines and the states of sleep. Science 163:32-41. CrossRef Medline

Kaufling J, Veinante P, Pawlowski SA, Freund-Mercier MJ, Barrot M (2009) Afferents to the GABAergic tail of the ventral tegmental area in the rat. J Comp Neurol 513:597-621. CrossRef Medline

Kessler RC, Berglund P, Demler O, Jin R, Koretz D, Merikangas KR, Rush AJ, Walters EE, Wang PS (2003) The epidemiology of major depressive disorder: results from the National Comorbidity Survey Replication (NCSR). JAMA 289:3095-3105. CrossRef Medline

Kiening K, Sartorius A (2013) A new translational target for deep brain stimulation to treat depression. EMBO Mol Med 5:1151-1153. CrossRef Medline

Kim U, Chang SY (2005) Dendritic morphology, local circuitry, and intrinsic electrophysiology of neurons in the rat medial and lateral habenular nuclei of the epithalamus. J Comp Neurol 483:236-250. CrossRef Medline

Krishnan V, Han MH, Graham DL, Berton O, Renthal W, Russo SJ, Laplant Q, Graham A, Lutter M, Lagace DC, Ghose S, Reister R, Tannous P, Green TA, Neve RL, Chakravarty S, Kumar A, Eisch AJ, Self DW, Lee FS, et al. (2007) Molecular adaptations underlying susceptibility and resistance to social defeat in brain reward regions. Cell 131:391-404. CrossRef Medline

Lee Y, Messing A, Su M, Brenner M (2008) GFAP promoter elements required for region-specific and astrocyte-specific expression. Glia 56:481493. CrossRef Medline

Lehre KP, Levy LM, Ottersen OP, Storm-Mathisen J, Danbolt NC (1995) Differential expression of two glial glutamate transporters in the rat brain: quantitative and immunocytochemical observations. J Neurosci 15:18351853. Medline

Levy LM, Lehre KP, Rolstad B, Danbolt NC (1993) A monoclonal antibody raised against an $[\mathrm{Na}(+)+\mathrm{K}+]$ coupled L-glutamate transporter purified from rat brain confirms glial cell localization. FEBS Lett 317:79-84. CrossRef Medline

Li B, Piriz J, Mirrione M, Chung C, Proulx CD, Schulz D, Henn F, Malinow R (2011) Synaptic potentiation onto habenula neurons in the learned helplessness model of depression. Nature 470:535-539. CrossRef Medline

Li K, Zhou T, Liao L, Yang Z, Wong C, Henn F, Malinow R, Yates JR 3rd, Hu H (2013) betaCaMKII in lateral habenula mediates core symptoms of depression. Science 341:1016-1020. CrossRef Medline

Ludwin SK, Kosek JC, Eng LF (1976) The topographical distribution of S-100 and GFA proteins in the adult rat brain: an immunohistochemical study using horseradish peroxidase-labelled antibodies. J Comp Neurol 165:197-207. CrossRef Medline

Mann JJ, Waternaux C, Haas GL, Malone KM (1999) Toward a clinical model of suicidal behavior in psychiatric patients. Am J Psychiatry 156: 181-189. Medline

Matsumoto M, Hikosaka O (2009) Representation of negative motivational value in the primate lateral habenula. Nat Neurosci 12:77-84. CrossRef Medline

Medina A, Burke S, Thompson RC, Bunney W Jr, Myers RM, Schatzberg A, Akil H, Watson SJ (2013) Glutamate transporters: a key piece in the glutamate puzzle of major depressive disorder. J Psychiatr Res 47:11501156. CrossRef Medline

Merali Z, Levac C, Anisman H (2003) Validation of a simple, ethologically relevant paradigm for assessing anxiety in mice. Biol Psychiatry 54:552565. CrossRef Medline

Meye FJ, Lecca S, Valentinova K, Mameli M (2013) Synaptic and cellular profile of neurons in the lateral habenula. Front Hum Neurosci 7:860. CrossRef Medline

Mineur YS, Picciotto MR, Sanacora G (2007) Antidepressant-like effects of ceftriaxone in male C57BL/6J mice. Biol Psychiatry 61:250-252. CrossRef Medline

Modell S, Lauer CJ (2007) Rapid eye movement (REM) sleep: an endophenotype for depression. Curr Psychiatry Rep 9:480 - 485. CrossRef Medline

Morris JS, Smith KA, Cowen PJ, Friston KJ, Dolan RJ (1999) Covariation of activity in habenula and dorsal raphe nuclei following tryptophan depletion. Neuroimage 10:163-172. CrossRef Medline

Mullen RJ, Buck CR, Smith AM (1992) NeuN, a neuronal specific nuclear protein in vertebrates. Development 116:201-211. Medline

Murphy TM, Ryan M, Foster T, Kelly C, McClelland R, O'Grady J, Corcoran E, Brady J, Reilly M, Jeffers A, Brown K, Maher A, Bannan N, Casement A, Lynch D, Bolger S, Tewari P, Buckley A, Quinlivan L, Daly L, et al. (2011) Risk and protective genetic variants in suicidal behaviour: association with SLC1A2, SLC1A3, 5-HTR1B \&NTRK2 polymorphisms. Behav Brain Funct 7:22. CrossRef Medline

Nair-Roberts RG, Chatelain-Badie SD, Benson E, White-Cooper H, Bolam JP, Ungless MA (2008) Stereological estimates of dopaminergic, GABAergic and glutamatergic neurons in the ventral tegmental area, substantia nigra and retrorubral field in the rat. Neuroscience 152:10241031. CrossRef Medline

Nitz D, Siegel J (1997) GABA release in the dorsal raphe nucleus: role in the control of REM sleep. Am J Physiol 273:R451-R455. Medline

Oh DH, Oh D, Son H, Webster MJ, Weickert CS, Kim SH (2014) An association between the reduced levels of SLC1A2 and GAD1 in the dorsolateral prefrontal cortex in major depressive disorder: possible involvement of an attenuated RAF/MEK/ERK signaling pathway. J Neural Transm 121:783-792. CrossRef Medline

Ortinski PI, Dong J, Mungenast A, Yue C, Takano H, Watson DJ, Haydon PG, Coulter DA (2010) Selective induction of astrocytic gliosis generates deficits in neuronal inhibition. Nat Neurosci 13:584-591. CrossRef Medline

Paxinos G, Franklin KB (2008) The mouse brain in stereotaxic coordinates, compact, Ed 3. Amsterdam: Elsevier Academic.

Popoli M, Yan Z, McEwen BS, Sanacora G (2011) The stressed synapse: the impact of stress and glucocorticoids on glutamate transmission. Nat Rev Neurosci 13:22-37. CrossRef Medline

Portas CM, Thakkar M, Rainnie D, McCarley RW (1996) Microdialysis perfusion of 8-hydroxy-2-(di- $n$-propylamino)tetralin (8-OH-DPAT) in the dorsal raphe nucleus decreases serotonin release and increases rapid eye movement sleep in the freely moving cat. J Neurosci 16:2820-2828. Medline

Rajkowska G, Miguel-Hidalgo JJ (2007) Gliogenesis and glial pathology in depression. CNS Neurol Disord Drug Targets 6:219-233. CrossRef Medline

Riemann D, Berger M, Voderholzer U (2001) Sleep and depression-results from psychobiological studies: an overview. Biol Psychol 57:67-103. CrossRef Medline

Roiser JP, Levy J, Fromm SJ, Nugent AC, Talagala SL, Hasler G, Henn FA, Sahakian BJ, Drevets WC (2009) The effects of tryptophan depletion on neural responses to emotional words in remitted depression. Biol Psychiatry 66:441-450. CrossRef Medline

Rothstein JD, Martin L, Levey AI, Dykes-Hoberg M, Jin L, Wu D, Nash N, Kuncl RW (1994) Localization of neuronal and glial glutamate transporters. Neuron 13:713-725. CrossRef Medline

Rothstein JD, Patel S, Regan MR, Haenggeli C, Huang YH, Bergles DE, Jin L, Dykes Hoberg M, Vidensky S, Chung DS, Toan SV, Bruijn LI, Su ZZ, Gupta P, Fisher PB (2005) Beta-lactam antibiotics offer neuroprotection by increasing glutamate transporter expression. Nature 433:73-77. CrossRef Medline

Santarelli L, Saxe M, Gross C, Surget A, Battaglia F, Dulawa S, Weisstaub N, Lee J, Duman R, Arancio O, Belzung C, Hen R (2003) Requirement of hippocampal neurogenesis for the behavioral effects of antidepressants. Science 301:805-809. CrossRef Medline

Sartorius A, Kiening KL, Kirsch P, von Gall CC, Haberkorn U, Unterberg AW, Henn FA, Meyer-Lindenberg A (2010) Remission of major depression under deep brain stimulation of the lateral habenula in a therapyrefractory patient. Biol Psychiatry 67:e9-e11. CrossRef Medline

Shibata T, Yamada K, Watanabe M, Ikenaka K, Wada K, Tanaka K, Inoue Y (1997) Glutamate transporter GLAST is expressed in the radial gliaastrocyte lineage of developing mouse spinal cord. J Neurosci 17:92129219. Medline

Solomon DA, Keller MB, Leon AC, Mueller TI, Shea MT, Warshaw M, Maser 
JD, Coryell W, Endicott J (1997) Recovery from major depression: a 10-year prospective follow-up across multiple episodes. Arch Gen Psychiatry 54:1001-1006. CrossRef Medline

Steiger A, Kimura M (2010) Wake and sleep EEG provide biomarkers in depression. J Psychiatr Res 44:242-252. CrossRef Medline

Takekawa T, Isomura Y, Fukai T (2012) Spike sorting of heterogeneous neuron types by multimodality-weighted PCA and explicit robust variational Bayes. Front Neuroinform 6:5. CrossRef Medline

Tanaka K, Watase K, Manabe T, Yamada K, Watanabe M, Takahashi K, Iwama H, Nishikawa T, Ichihara N, Kikuchi T, Okuyama S, Kawashima N, Hori S, Takimoto M, Wada K (1997) Epilepsy and exacerbation of brain injury in mice lacking the glutamate transporter GLT-1. Science 276:1699-1702. CrossRef Medline

Taylor SE, Stanton AL (2007) Coping resources, coping processes, and mental health. Annu Rev Clin Psychol 3:377-401. CrossRef Medline

Tye KM, Mirzabekov JJ, Warden MR, Ferenczi EA, Tsai HC, Finkelstein J, Kim SY, Adhikari A, Thompson KR, Andalman AS, Gunaydin LA, Witten IB, Deisseroth K (2013) Dopamine neurons modulate neural encoding and expression of depression-related behaviour. Nature 493:537-541. CrossRef Medline

Wilcox KS, Gutnick MJ, Christoph GR (1988) Electrophysiological proper- ties of neurons in the lateral habenula nucleus: an in vitro study. J Neurophysiol 59:212-225. Medline

Wise RA (2004) Dopamine, learning and motivation. Nat Rev Neurosci 5:483-494. CrossRef Medline

Yagi H, Ogura T, Mizukami H, Urabe M, Hamada H, Yoshikawa H, Ozawa K, Kume A (2011) Complete restoration of phenylalanine oxidation in phenylketonuria mouse by a self-complementary adeno-associated virus vector. J Gene Med 13:114-122. CrossRef Medline

Yamada K, Watanabe M, Shibata T, Nagashima M, Tanaka K, Inoue Y (1998) Glutamate transporter GLT-1 is transiently localized on growing axons of the mouse spinal cord before establishing astrocytic expression. J Neurosci 18:5706-5713. Medline

Yang LM, Hu B, Xia YH, Zhang BL, Zhao H (2008) Lateral habenula lesions improve the behavioral response in depressed rats via increasing the serotonin level in dorsal raphe nucleus. Behav Brain Res 188:84-90. CrossRef Medline

Zink M, Vollmayr B, Gebicke-Haerter PJ, Henn FA (2010) Reduced expression of glutamate transporters vGluT1, EAAT2 and EAAT4 in learned helpless rats, an animal model of depression. Neuropharmacology 58: 465-473. CrossRef Medline 